\title{
SIMULATION AND INTERPRETATION OF THE GENESIS OF TROPICAL STORM GERT (2005) AS PART OF THE NASA TROPICAL CLOUD SYSTEMS AND PROCESSES EXPERIMENT
}

Scott A. Braun, M. T. Montgomery, and Kevin Mallen

Submitted to Journal of the Atmospheric Sciences for a special issue on NASA's TCSP and NAMMA field programs.

\section{Popular Summary}

Several hypotheses have been put forward for the how tropical cyclones (tropical storms and hurricanes in the Atlantic) first develop circulation at the surface, a key event that needs to occur before a storm can begin to draw energy from the warm ocean. One hypothesis suggests that the surface circulation forms from a "top-down" approach in which a storm's rotating circulation begins at middle levels of the atmosphere and builds down to the surface through processes related to light "stratiform" (horizontally extensive) precipitation. Another hypothesis suggests a bottom-up approach in which deep thunderstorm towers (convection) play the major role in spinning up the flow at the surface. These "hot towers" form in the area of the mid-level circulation and strongly concentrate this rotation at low levels within their updrafts. Merger of several of these hot towers then intensifies the surface circulation to the point in which a storm forms. This paper examines computer simulations of Tropical Storm Gert (2005), which formed in the Gulf of Mexico during the National Aeronautics and Space Administration's (NASA) Tropical Cloud Systems and Processes (TCSP) Experiment, to investigate the development of low-level circulation and, in particular, whether stratiform or hot tower processes were responsible for the storm's formation. Data from NASA satellites and from aircraft were used to show that the model did a good job of reproducing the formation and evolution of Gert. The simulation shows that a mix of both stratiform and convective rainfall occurred within Gert. While the stratiform rainfall clearly acted to increase rotation at middle levels, the diverging outflow beneath the stratiform rain worked against spinning up the low-level winds. The hot towers appeared to dominate the low-level flow, producing intense rotation within their cores and often being associated with significant pressure falls at the surface. Over time, many of these hot towers merged, with each merger adding to the rotation of the storm and the pressure falls at the surface. This process continued to increase the strength of the storm until the storm made landfall on the east coast of Mexico. These results support the bottom-up hypothesis for development. 


\section{SIMULATION AND INTERPRETATION OF THE GENESIS OF TROPICAL STORM GERT (2005) AS PART OF THE NASA TROPICAL CLOUD SYSTEMS AND PROCESSES EXPERIMENT}

Scott A. Braun

Laboratory for Atmospheres, NASA Goddard Space Flight Center, Greenbelt, Maryland

Michael T. Montgomery

Naval Postgraduate School, Monterey, California and NOAA/AOML Hurricane Research Division, Miami, Florida

Kevin Mallen,

Department of Atmospheric Sciences, Colorado State University, Fort Collins, Colorado

Submitted to the Journal of the Atmospheric Sciences

as part of a special issue on the NASA TCSP and NAMMA Field Programs on

March 5, 2009

Corresponding author: Scott Braun, NASA/GSFC, Code 613.1, Greenbelt, MD 2077.

Scott.A.Braun@nasa.gov 


\begin{abstract}
Several hypotheses have been put forward for the mechanisms of generation of surface circulation associated with tropical cyclones. This paper examines high-resolution simulations of Tropical Storm Gert (2005), which formed in the Gulf of Mexico during National Aeronautics and Space Administration's (NASA) Tropical Cloud Systems and Processes (TCSP) Experiment, to investigate the development of low-level circulation and its relationship to the precipitation evolution. Two simulations are examined; one that better matches available observations but underpredicts the storm's minimum sea-level pressure and a second one that somewhat overintensifies the storm, but provides a set of simulations that encapsulates the overall genesis and development characteristics of the observed storm.
\end{abstract}

The roles of convective and stratiform precipitation processes within the mesoscale precipitation systems that formed Gert are discussed. During July 21-25, two episodes of convective system development occurred. In each, convective system evolution was characterized by intense and deep convective upward motions followed by increasing stratiformtype vertical motions (upper-level ascent, low-level descent). Potential vorticity in convective regions was strongest at low levels while stratiform-region PV was strongest at mid levels, suggesting that convective processes acted to spin up lower levels prior to the spin up of middle levels by stratiform processes. Intense vortical hot towers (VHTs) were prominent features of the low-level cyclonic vorticity field. The most prominent PV anomalies persisted more than $6 \mathrm{~h}$ and often were associated with localized minima in the sea-level pressure field. A gradual segregation of the PV occurred, with cyclonic PV moving inward and anticyclonic PV moving outward from the storm center. Existing VHTs near the center continually merged with new VHTs, gradually increasing the mean vorticity near the center. Nearly concurrently with this 
VHT-induced development, stratiform precipitation processes strongly enhanced the mean inflow and convergence at middle levels, rapidly increasing the mid-level vorticity. However, the stratiform vertical motion profile is such that while it increases mid-level vorticity, it decreases vorticity near the surface as a result of low-level divergence. Consequently, the results suggest that while stratiform precipitation regions may significantly increase cyclonic circulation at midlevels, convective vortex enhancement at low to mid-levels is likely necessary for genesis. 


\section{Introduction}

Large-scale influences on tropical cyclogenesis have been studied for many years. There is general agreement that tropical cyclones form in the tropics or subtropics over sufficiently warm (> 26C) water possessing sufficiently great depth, far enough from the equator that background rotation is sufficient, in regions of high relative humidity, and when vertical wind shear over the depth of the troposphere is relatively small (Gray 1975, 1979). In addition, tropical cyclones form within regions of pre-existing cyclonic relative vorticity in the lower troposphere, e.g., easterly waves, a monsoon trough, or the active part of the Madden-Julian Oscillation (Roundy and Frank 2004).

The above conditions become more difficult to apply when one considers the mesoscale evolution of actual forming tropical cyclones. Tropical storms are generally spawned from mesoscale convective system (MCS) precursors within the pre-existing region of cyclonic vorticity noted above (Velasco and Fritsch 1987; Gray 1998). Midlevel convergence into large stratiform precipitation regions within MCSs, along with tilting of horizontal vorticity into the vertical, provides a source of concentrated midlevel vorticity (Gamache and Houze 1982; Verlinde and Cotton 1990; Brandes and Ziegler 1993; Chen and Frank 1993; Bister and Emanuel 1997; Chong and Bousquet 1999; Yu et al. 1999) that often becomes the precursor to surface development. Although MCSs occur frequently over the tropical oceans, only a few develop into tropical cyclones and the mechanisms that inhibit or favor development are still poorly understood. Over the last decade and a half, the focus on the genesis problem became the search for a mechanism responsible for the development of low-level vorticity below the MCS of sufficient intensity to initiate the wind-induced surface heat exchange (WISHE) process of Emanuel (1987). Several studies have proposed mechanisms for the generation of sufficient 
surface cyclonic vorticity by some form of vorticity transport or projection downwards from the mid-levels. These are the so-called "top-down" theories of Bister and Emanuel (1997), Ritchie and Holland (1997), and Simpson et al. (1997). Bister and Emanuel (1997) proposed that a mesoscale region of light rainfall, or stratiform rain, would act to humidify the low-level air, thereby gradually lowering the level of peak cooling, and hence potential vorticity production, to the surface. The key element in this hypothesis is the requirement of a stratiform precipitating region that cools and moistens the lower troposphere and descent of the cyclonic vortex to near the surface to the point at which the effects of cold downdrafts no longer inhibit development of cyclonic winds at the surface. Ritchie and Holland (1997) and Simpson et al. (1997) proposed a vortex merger theory in which successive mergers of mid-level mesoscale vortices (generally thought to be associated with the stratiform regions of MCSs) intensified the mid-level vortex. A consequence of the mid-level merger process is an increase in the horizontal and vertical scale of the vortex. They proposed genesis would begin when the vertical scale had increased sufficiently to reach the surface.

Hendricks et al. (2004) and Montgomery et al. (2006) have proposed an entirely different "bottom-up" deep-convection route to cyclogenesis that blends moist thermodynamical and dynamical processes and operates between the development of a weak cyclonic circulation near the sea surface and the ignition of the WISHE [wind-induced surface heat exchange, Emanuel (1986)] mechanism. In their high resolution numerical simulations, Montgomery et al. (2006) found that deep convective towers possessing intense cyclonic vorticity in their cores are the dominant coherent structures of a pre-depression disturbance. These vortical hot towers (VHTs) sustain themselves by consuming available potential energy in their local environment and by merging with neighboring towers. The population of VHTs statistically mimics a quasi-steady 
heating rate in the core of the mesoscale vortex and generates a system-scale transverse circulation with low-level inflow and upper-level outflow. The low-level inflow concentrates the pre-existing and VHT-generated absolute cyclonic vorticity to a sufficient amplitude to start the hurricane heat engine.

Of course, the hypotheses above are not mutually exclusive. They suggest that tropical cyclones can form from one or multiple midlevel mesoscale vortices that themselves may contain an ensemble of VHTs. For these vortices to amplify the surface circulation, the core of the system likely must have sufficiently high relative humidity so that downdrafts do not inhibit development. This high humidity may often result from mesoscale stratiform precipitation regions that are associated with the mesoscale vortices. Steranka et al. (1986), Zehr (1992), and Rodgers et al. (1994) find evidence from satellite data that in many tropical cyclones, sustained convective bursts precede rapid intensification. These bursts might be associated with the influence of vertical wind shear or some other physical process. It is possible that convective bursts represent longer-lived VHTs and so are extremely favorable for cyclogenesis and intensification. The sequence of processes by which an MCS with embedded mesoscale vortices and VHTs develops into a tropical cyclone is still not well understood, but it should depend significantly upon the organization of convective and stratiform precipitation within the tropical disturbance.

Tory et al. (2006a, 2006b), using output from the Tropical Cyclone Limited Area Prediction System (TC-LAPS, with $0.15^{\circ}$ horizontal resolution), determined that the primary vortex enhancement mechanisms in the model were convergence/stretching and vertical advection of absolute vorticity in deep convective updrafts. Secondary vortex enhancement mechanisms were associated with vortex upscale cascade, or mergers of multiple convective 
vortices into a single larger vortex, and system-scale intensification via enhancement of the secondary circulation by convective heating. They argued that while stratiform precipitation regions may significantly increase cyclonic circulation at mid-levels, convective vortex enhancement at low to mid-levels is likely necessary for genesis. However, stratiform precipitation was largely absent from the TC-LAPS simulations because of the coarse resolution and lack of explicit cloud microphysical processes. The vertical motions were dominated by large deep convective cores that may have biased the divergence profiles toward convective, rather than stratiform, profiles.

Given these uncertainties regarding the relative roles of convective and stratiform precipitation regions in cyclogenesis, in July 2005, NASA conducted the Tropical Cloud Systems and Processes (TCSP) field experiment in collaboration with the National Oceanic and Atmospheric Administration's (NOAA) Hurricane Research Division (HRD) to study tropical cloud systems and tropical cyclone genesis and evolution in the Eastern Pacific and western Caribbean (Halverson et al. 2007). A major objective of the TCSP experiment was the improvement of the understanding and prediction of tropical cyclone genesis using remote sensing and in-situ data, as well as numerical modeling, particularly as they relate to the three phases of water and the organization of precipitation. On July 23-25, the NASA ER-2 and NOAA P-3 aircraft flew repeated missions into a tropical wave that eventually transformed into Tropical Storm Gert before making landfall in Mexico along the western Gulf coast. A future paper by Mallen et al. will present a detailed observational analysis of the formation and evolution of Gert. This study describes a numerical modeling study of the genesis of Gert, with an emphasis on the evolution of its precipitation, kinematic, and thermodynamic structures. Specifically, we seek to elucidate the roles of well-resolved convective and stratiform 
precipitation processes in the generation of potential vorticity within the storm and the development of surface circulation leading to genesis.

\section{Methodology and data description}

\section{a. Model set up}

This study employs the Advanced Research version of the Weather Research and Forecasting (WRF) modeling system (Version 2.2, Skamarock et al. 2005) to conduct simulations of the genesis of Tropical Storm Gert. Four grids nesting down to $2 \mathrm{~km}$ horizontal grid spacing (see

Fig. 1) are employed in order to adequately represent the convection. The outer grid has a horizontal grid spacing of $54 \mathrm{~km}$ and contains $150 \times 90$ grid points in the $x$ - and $y$-directions. The grid is centered at $91.1^{\circ} \mathrm{W}, 22.9^{\circ} \mathrm{N}$ and uses a Mercator map projection. Two stationary nested meshes are used with the following grid spacings and grid dimensions: $18 \mathrm{~km}$ and $226 \times 178$, and $6 \mathrm{~km}$ and $400 \times 340$. The third nest is designed to move with the storm and has a grid spacing of 2 $\mathrm{km}$ and dimensions of $400 \times 400$ grid points. All grids use 31 vertical levels. Physics options include the Yonsei University boundary layer scheme (Noh et al. 2003; Hong et al. 2006), the MM5 similarity-theory surface-layer scheme (Zhang and Anthes 1982; Skamarock et al. 2005), the Noah land-surface scheme (Chen and Dudhia 2001), the Kain-Fritsch cumulus scheme (Kain and Fritsch 1990, 1993; Skamarock et al. 2005) on the 54- and 18-km grids only and calculated every time step, and the WRF Single Moment 6-class cloud microphysics (Hong et al. 2004) on all grids. Radiative processes are calculated every 5 minutes on the 54- and 18-km grids and 2 min on the 6- and 2-km grids using the Rapid Radiative Transfer Model longwave (Mlawer et al 1997) and Dudhia shortwave (Dudhia 1989) schemes. 
Initial and boundary conditions are obtained from 6-hourly National Centers for Environmental Prediction Global Forecast System (GFS) analyses with $1^{\circ}$ resolution using the WRF Preprocessing System software. Experiments were run with multiple initialization times to determine which times provided the best reproduction of the evolution of Gert as verified by aircraft and satellite observations. In this study, results are shown for two simulations. The primary simulation (designated the I2206 run) is started at 06 UTC 22 July 2005 and run for 66 hours until 00 UTC 25 July. This simulation verifies well against observations, but produces a weaker surface pressure minimum at landfall than is observed. A second simulation (designated the $\mathrm{I} 2112$ run) is started at 12 UTC 21 July and is discussed in section 6. This simulation produces a stronger vortex and more active convection at early stages (22-23 July) that is less consistent with observations at these times, but leads to a more organized system with minimum surface pressures that are somewhat lower than observed values. Whereas these two simulations clearly do not constitute a large sample of a possible ensemble, they encapsulate the overall genesis and development characteristics observed. We consequently believe these two simulations are adequate for answering the primary scientific questions raised in the introduction.

\section{b. TCSP airborne validation data}

The NASA TCSP field experiment included research flights with the NASA ER-2 highaltitude aircraft, typically flying at $\sim 20 \mathrm{~km}$ altitude, and two NOAA WP-3 Orion aircraft flying near $650 \mathrm{hPa}(\sim 3.5 \mathrm{~km})$. For Tropical Storm Gert, five missions were conducted over the life cycle of the storm, from when the disturbance was a tropical wave over the Yucatan Peninsula to shortly after landfall as a tropical storm. Two of the missions involved coordinated flights with the ER-2 and one P-3 aircraft, with the remainder being single aircraft missions. In addition to 
the flights associated with the TCSP experiment, an Air Force reconnaissance flight occurred from 0849-1736 UTC 24 July, thus providing greater continuity of measurements during the lifecycle of Gert. Table 1 provides a summary of the different flights. Early on July 23, the NASA ER-2 and NOAA P-3 flew a coordinated mission in the vicinity of intense convection east of the Yucatan Peninsula and then sampled the structure of the easterly wave along the northern coast of the peninsula. A second P-3 flight was conducted later that day and surveyed the easterly wave as it moved west of the peninsula and transitioned into a depression. During this period, convection was weak and scattered in the region. Early on July 24, intense convection developed over the Gulf of Mexico in association with the depression. Coordinated flights of the ER-2 and P-3 characterized the wind and precipitation structure of the depression as it strengthened into a tropical storm. Portions of the mission focused on sampling the rapidly intensifying convection to determine the role of convective bursts in the genesis process. A solo P-3 flight continued to investigate Gert as the storm neared the coast of Mexico late on July 24. This was followed by a solo ER-2 flight to investigate Gert's landfall on the July 25.

In this study, we focus primarily on the wind information from dropsondes from the NOAA P-3 aircraft as well as the flight-level winds from the Air Force flight on 24 July. Dropsonde winds at several levels are overlaid on model-derived wind fields in order to validate the simulated wind fields. Because the dropsonde data are collected over an approximately 8-h period, but are compared to simulated winds at a single time (typically the mid-point of the flight period), there is an implicit assumption that the wind field is approximately stationary during the period of the flight.

\section{Simulation results and validation}

\section{a. Storm evolution}


This section focuses on the evolution of the simulated development of Tropical Storm Gert through a description of the simulated low-level wind and precipitation fields. Figure 2 shows simulated radar reflectivity and $850-\mathrm{hPa}$ geopotential height and winds from the 6-km grid for four different times. At 12 UTC 22 July (Fig. 2a), 6 h after initialization, the large-scale pattern is characterized by a low pressure system stretching from the eastern Pacific across Honduras to the western Caribbean, with intense convection near the trough axis to the east of the Yucatan Peninsula. The convective system had moved up from the Panama region over the previous few days. The low-level flow over the Gulf of Mexico was generally easterly, which was largely blocked by the Sierra Madre mountains of Mexico and diverted southward, producing a barrier jet along the coast of the western Gulf that was present for most of the duration of the simulation. By 00 UTC 23 July (not shown), the low moved over the southern portion of the Yucatan Peninsula as convective activity began to diminish. At 12 UTC 23 July (Fig. 2b), a weak low was emerging over the Bay of Campeche. Convection over the Bay was generally weak and scattered within the trough to the north and west of the circulation center. By 00 UTC 24 July (not shown), the slowly strengthening circulation around the low center had moved northwestward, with weak-to-moderate convection occurring just to the north of the low. Six hours later (06 UTC 24 July, Fig. 2c), convection rapidly increased in both intensity and area in general agreement with GOES data (not shown). Over the next 12 h (Fig. 2d), the increased convective activity led to the slow development of the system into a tropical storm by landfall.

A more detailed depiction of the evolution of the simulated precipitation and low-level winds is provided in Fig. 3, which shows simulated radar reflectivity ${ }^{1}$ and vector winds at $500 \mathrm{~m}$ for selected times. Six hours into the simulation (Fig. 3a), intense deep convection developed

\footnotetext{
${ }^{1}$ See footnote 2 of Braun et al. (2006) for a description of the reflectivity calculation.
} 
along and offshore of the Belize coast, similar to TRMM-observed convection at this time (not shown) except that the northwest-southeast oriented band was observed to be much further northward (not shown). The center of cyclonic circulation was located along the Honduran coastline at the end of the hook-shaped convective system. At 18 UTC 22 July (Fig. 3b), the center of circulation was along the Belize coast and convection was beginning to diminish as the system moved inland. As the circulation moved into the southern Bay of Campeche by 12 UTC 23 July (Fig. 3c), there were scattered areas of convection over the Gulf, much of it fairly shallow (below $\sim 5 \mathrm{~km}$ ). By 18 UTC 23 July (Fig. 3d), the circulation continued to drift northwestward as some convection developed north of the center. Westerly flow just south of the center was very weak and, by 00 UTC 24 July (Fig. 3e), was replaced by weak easterly flow such that the closed circulation was absent as viewed in an earth-relative reference frame. In a frame of reference moving with the wave disturbance, however, a closed circulation is seen to emerge around this time in the lower troposphere (not shown). The emergence of a closed circulation in the wave frame is thought to be a critical ingredient for a successful wave-tovortex transformation (Dunkerton et al. 2008). This boundary demarcating the closed circulation is an approximate material boundary that acts to reduce dry-air intrusion and contain moisture lofted by deep convection, such as VHTs (Dunkerton et al. 2008).

Two regions of more intense precipitation were present at 00 UTC 24 July. The first was just west of the trough axis along a convergence zone where the northerly flow associated with the trough met the low-level barrier jet east of the mountains. The second was an area of organizing deep convection embedded within the strong southeasterly flow on the eastern side of the trough. Convection began to rapidly expand by 06 UTC 24 July (Fig. 3f). In the southwestern Bay of Campeche, the easterly flow to the east of the trough axis encountered the northwesterly 
barrier jet, leading to an enhancement of convergence and convection, as well as reforming the closed cyclonic circulation (in an earth-based reference frame) farther north. Convection surrounded the center of circulation with weaker flow within and stronger flow without. By 12 UTC (Fig. 3g), convection intensified around the center of circulation, which elongated in the north-south direction and shifted southward somewhat so that it was on the north side of intense convection that had formed on the border of the barrier jet. Over the next six hours (Fig. 3h), convection on the east side of the circulation dissipated or moved northward while convection on the west side was enhanced along the coastline. The center of circulation eventually made landfall at approximately 23 UTC 24 July, within a few hours of the observed landfall at or just after 00 UTC 25 July.

\section{b. Observational validation}

In this section, we provide validation of the model using data from the NOAA P-3 Orion and Air Force reconnaissance aircraft flights into Gert, as well as data from the NASA TRMM and Quikscat satellites. While a wealth of other data were available, here we show only those data that provide critical validation of key features of the storm's evolution, with an emphasis on winds and precipitation.

The Quikscat satellite passed over the Gulf of Mexico three times during the genesis of Gert. Wind retrieval accuracy is impacted by rainfall as a result of scattering and attenuation of the transmitted energy by rain as well as effects of the rain on the surface roughness of the ocean. In rainy areas, the retrieved wind is generally too large by an amount that is proportional to the rain rate (Portabella and Stoffelen 2001). For rain rates above $6 \mathrm{~mm} \mathrm{~h}^{-1}$, as determined by Special Sensor Microwave Imager data, Portabella and Stoffelen (2001) suggested that the Quikscat wind vector cells contained no useful wind information. While plots of the Quikscat data in Fig. 
4 include all of the available wind data, areas having more than a $50 \%$ probability of rain are indicated to highlight areas of possible rain contamination. At 00 UTC 23 July (Fig. 4a), the wind field was characterized by a broad area of weak northeasterly flow. Wind vectors just off the western coast of the Yucatan Peninsula suggest a cyclonic disturbance over the peninsula. The model wind field at this time (Fig. 5a) is very similar to the Quikscat wind field. At 12 UTC 23 July (Fig. 4b), the center of circulation is along the southern coast of the Bay of Campeche between $92-93^{\circ} \mathrm{W}$ and a well-defined convergence zone is present where the flow on the western side of the trough encounters offshore-directed flow that the model suggests is related to topographic blocking. This pattern is qualitatively similar to the corresponding simulated wind field (Fig. 5b), but with somewhat stronger wind speeds. Although the wind vectors are to some degree contaminated by rain along the western coast, the Quikscat data suggest a greater offshore extent of the barrier flow than seen in the simulation. By 01 UTC 24 July (Fig. 4c), a welldefined center of the cyclonic circulation has formed with wind speeds surrounding raincontaminated regions between $12-16 \mathrm{~m} \mathrm{~s}^{-1}$. The model has not yet developed such a closed circulation by 00 UTC 24 July (Fig. 5c), but does do so by 06 UTC (Fig. 5d). The strong westerly winds observed by Quikscat on the southwestern side of the circulation are qualitatively very similar to, but somewhat stronger than, those produced by the model. Thus, the Quikscat winds indicate that the evolution of the surface winds within the model is reasonable; however, the delay in forming the closed circulation in an earth-relative reference frame suggests either an error in the intensity of the vortex or the strength of the mean flow, or both.

Figure 6 shows simulated wind speeds and wind barbs for 21 UTC 23 July with observed dropsonde winds overlaid. The dropsonde data were obtained during a P3 flight spanning 16 UTC 23 July to 01 UTC 24 July. At this time, the simulated wind field at $1000 \mathrm{hPa}$ (Fig. 6a) is 
characterized by the cyclonic circulation along the southern Gulf coast and a trough extending northward over the southern Gulf of Mexico. The barrier jet is apparent in the strong northerly winds seen along the topography on the western side of the trough. A dropsonde released in the western Bay of Campeche is consistent with the barrier flow. The simulated winds at all three levels shown are in good agreement with the dropsonde data with the exception of the weak westerly wind seen near the center of circulation at $1000 \mathrm{hPa}$ and the suggestion that the simulated trough axis is somewhat further westward than that indicated by the dropsondes.

Figure 7 compares simulated winds at 05 UTC 24 July with dropsonde data obtained from a flight spanning 0030-0930 UTC 24 July. While not well defined at $1000 \mathrm{hPa}$ at this time, a closed circulation in the simulation develops near $95.25^{\circ} \mathrm{W}, 20.75^{\circ} \mathrm{N}(x=185, y=165)$, fairly close to the center location suggested by the dropsondes. Simulated flow to the northeast of the center is more southerly than indicated by the dropsondes. A dropsonde near $95.0^{\circ} \mathrm{W}, 19.0^{\circ} \mathrm{N}$ $(\mathrm{x}=200, \mathrm{y}=70)$ suggests, as in Fig. 6 , that the trough may be moving westward too rapidly and that the simulated barrier jet may not extend sufficiently eastward. A similar pattern is seen at $850 \mathrm{hPa}$. Dropsonde winds at $1000 \mathrm{hPa}$ indicate a closed circulation near $95.25^{\circ} \mathrm{W}, 20.75^{\circ} \mathrm{N}$, but this closed circulation is apparently very shallow as it is not seen in the dropsonde data at 850 $\mathrm{hPa}$ and above (Figs. 7b, 7c). Data from two dropsondes in the western Bay of Campeche show strong northwesterly flow at $1000 \mathrm{hPa}$ and a more northerly direction at $850 \mathrm{hPa}$, consistent with a barrier jet that is weakening with height. A closed circulation is not yet apparent in the simulation at $700 \mathrm{hPa}$. Dropsonde winds at $700 \mathrm{hPa}$ do not indicate (but also do not exclude) the presence of a closed circulation.

Because the storm moved westward somewhat more rapidly than observed, the dropsonde winds in Fig. 8, corresponding to approximately 21 UTC 24 July (flight hours were 
from 17 UTC 24 July to 01 UTC 25 July), are compared to the simulated fields at 17 UTC 24 July because at this time the simulated storm was centered at nearly the same longitude as the observed storm at the later time. At this time, a closed cyclonic circulation is seen at all levels up to about $400 \mathrm{hPa}$ (not shown). The strongest winds are generally found on the northeastern side of the storm over a fairly broad region. If one allows for the time difference between simulation and observations, then the simulated winds can be said to be in good general agreement with the dropsonde data.

The TRMM satellite passed over Gert at 1430 UTC 24 July during a time when Air Force reconnaissance was flying in the boundary layer within the storm. This flight path, as well as a sample of flight-level winds, are overlaid on the TRMM rainfall rates in Fig. 9a. Note that rainfall rates are derived from the TRMM precipitation radar (PR) within its narrow swath (indicated by thin blue lines), while elsewhere the rain rates are retrieved from the TRMM microwave imager (TMI). The most intense rainfall is found in the eastern portion of the rainband on the southern side of the storm $\left(\sim 95.75^{\circ} \mathrm{W}, 20.3^{\circ} \mathrm{N}\right)$. This result is true even if the PR data is excluded (not shown), in which case the TMI rainfall rates in this area would be slightly greater than $20 \mathrm{~mm} \mathrm{~h}^{-1}$. The Air Force flight-level winds show strong westerly flow within the southern rainband and indicate a center of circulation near the northeast edge of the band near the most intense convection. Further north is a wide area of lighter precipitation with embedded convective cores (TMI rainfall rates $>10 \mathrm{~mm} \mathrm{~h}^{-1}$ ), while to the east is a rainband with relatively low rainfall rates (PR rainfall rates $<20 \mathrm{~mm} \mathrm{~h}^{-1}$ ). Simulated rainfall rates, along with $500-\mathrm{m}$ level wind barbs for a boxed-in region comparable to that in Fig. 9a, are shown for the same time in Fig. 9b. In many respects, the model compares quite favorably with the observations. The overall rainfall pattern is quite similar to that observed by TRMM with a prominent rainband with 
intense convection on the southern side of the storm, a wide area of precipitation to the north, and a rainband to the east. Furthermore, the simulated winds clearly indicate a center of circulation coinciding with the northern edge of the southern rainband with strong westerlies within the rainband. We can also note some differences: somewhat more intense convection scattered throughout the storm (compare to rainfall rates within the PR swath), particularly in the north-south oriented band to the east of the center; and weaker winds in the simulation compared to Air Force recon measurements, suggesting an underdevelopment of the storm circulation at this time.

As a final comparison, Fig. 10 shows the simulated minimum sea-level pressure along with the observed Best Track value. The observed value may contain considerable uncertainty given the limited sampling of the storm during its evolution. The observations suggest nearly continuous deepening of the storm from 1011 to $1005 \mathrm{hPa}$ beginning at 18 UTC 23 July, when Gert became a named storm, and ending at 00 UTC 25 July, when the storm made landfall. The simulation showed little tendency for deepening until about 06 UTC 24 July, when significant deep convection began, subsequently deepening from 1012 to $1008 \mathrm{hPa}$. On the basis of the foregoing findings, we conclude that the storm development was delayed and weaker relative to the observations.

\section{The relative roles of convective and stratiform processes}

In this section, we investigate the evolution of the mean vortex and the role that convective and stratiform precipitation processes play in this evolution. Simulation results are examined in a reference frame centered on the storm. When possible, the storm center is estimated using an approach similar to that described in Braun (2002) and Braun et al. (2006), but here minimizing the asymmetry of the $850 \mathrm{hPa}$ geopotential height instead of sea-level 
pressure. Because the storm is weak, there is considerable uncertainty in the center position. At early times, generally prior to 09 UTC 22 July, the geopotential height field provides a poor indicator of the disturbance position, so the approximate center of the developing convective system is used instead. To minimize the impact of this uncertainty in center location, results below show time series of profiles of area-averaged quantities, averaged within a radius of 300 $\mathrm{km}$. Fields of tangential and radial velocities must be viewed with some caution, especially at earlier times (e.g., prior to 12 UTC 23 July), since their values are dependent upon the derived center locations, while other fields simply reflect the evolution of the convective system and its near environment.

Figure 11 shows time series of the area averages of several quantities for the I2206 simulation beginning at 06 UTC 22 July and ending at 00 UTC 25 July. The vertical motion (Fig. 11a) shows the initial burst of ascent prior to 12 UTC 22 July as precipitation develops on the eastern side of the Yucatan Peninsula (cf. Fig. 3a). Convection weakened during the later part of July 22 and the early part of July 23 (Figs. 3b, 3c), transitioning to mean downward motion at middle to upper levels around 12 UTC 23 July. Convection resumed around 18 UTC 23 July (Fig. 3d) and then increased substantially by 06 UTC 24 July (cf. Fig. 3f). After 12 UTC 24 July, decreasing low-level upward motion and increasing upward motion aloft indicated a growing influence of stratiform precipitation processes.

In order to better delineate the roles of convective and stratiform processes during the simulation, Fig. 12 shows the area-weighted averages of vertical motion for convective, stratiform, and non-precipitating (at the surface) regions. The separation into convective and stratiform components was accomplished using a method similar to Tao et al. (1993). First, all grid points with surface rainfall rates greater than $20 \mathrm{~mm} \mathrm{~h}^{-1}$ were classified as convective. Next, 
a texture algorithm was used, where grid points having rainfall rates twice as large as the average of their nearest 24 neighbors were classified as convection. If a grid point is designated as convective in this way, then its nearest neighbors (within one grid distance) are also designated as convective. In order to identify convective columns in which significant precipitation was not yet reaching the surface, columns with upward vertical motions $>3 \mathrm{~m} \mathrm{~s}^{-1}$ or cloud liquid water $>0.5 \mathrm{~g} \mathrm{~kg}^{-1}$ were also denoted as convective. All remaining grid columns with surface precipitation greater than $0.1 \mathrm{~mm} \mathrm{~h}^{-1}$ were classified as stratiform, while remaining grid columns were classified as environment or non-precipitating anvil. The fields shown in Fig. 12 depict the averages over each region weighted by the fraction of the total number of grid columns in each classification. The sum of Figs. 12a-c yield the average vertical motion in Fig. 11a.

Figure 12 shows that, upon start up of the model, the initial precipitation development is stratiform in character, caused by large-scale saturated ascent (due to the initialization with coarse fields from the NCEP analysis). Within a few hours, small scale structure emerges in the form of deep convection that tends to dominate the vertical mass flux until about 12 UTC 22 July. By that time, a stratiform precipitation region forms in association with the deep convection and is associated with weak upward motion peaking at $300 \mathrm{hPa}$ and weak descent below 550 hPa. Strong subsidence also occurs in the environment of the initial convection, with peak downward motion at heights between $300-200 \mathrm{hPa}$. Convection weakens early on the $23^{\text {rd }}$, with negligible mean ascent or with mean subsidence found at mid to upper levels and with somewhat shallow convection (cf. Fig. 3c) below $600 \mathrm{hPa}$. Weak, deep convection develops late on July 23, with strong deep convection beginning around 03 UTC 24 July. Mean convective ascent peaks around 12 UTC 24 July and then weakens, although localized regions of strong ascent continue 
near the storm center through the end of the simulation ${ }^{2}$. Mean stratiform ascent at upper levels and descent below $500 \mathrm{hPa}$ develops around 21 UTC 23 July, intensifies rapidly after 06 UTC 24 July, and peaks near 15 UTC on the $24^{\text {th }}$. In the non-precipitating region, mean ascent develops in non-precipitating anvils after 12 UTC 24 July.

The tangential flow (Fig. 11b) shows that the cyclonic circulation extended vertically from the surface to between 300 and $400 \mathrm{hPa}$, and had peak tangential velocities near the top of the boundary layer. Anticyclonic flow occurred above $300 \mathrm{hPa}$. The vortex was relatively strong at 12 UTC 22 July as a result of the convection on the east side of the Yucatan Peninsula prior to that time. As the storm moved over the peninsula during the later part of July 22 and early part of July 23 , both the convection and the tangential velocities weakened. The weakening of the midlevel tangential velocities during this time does not necessarily reflect a weakening of the circulation (notice that the average PV does not change much in Fig. 11f). Instead, it appears to result from a slower westward movement of high-PV air at mid levels ( $500 \mathrm{hPa})$ compared to air at low levels $(\sim 850 \mathrm{hPa})$, thereby producing an eastward tilt of the system. Since the radius of maximum winds was still quite large during this time, this eastward tilt of the storm resulted in stronger winds at mid levels being shifted out of the averaging domain, thus lowering the average tangential wind speed. The resumption of convection, first just after 12 UTC 23 July and then more intensely after 00 UTC 24 July, led to a realignment of the lower and mid-level circulations as well as a simultaneous intensification of the lower and mid-level tangential flow. Beginning around 12 UTC 24 July, when stratiform ascent was strong, rapid intensification of the mid-level flow began.

\footnotetext{
${ }^{2}$ When the averaging radius is reduced to $150 \mathrm{~km}$, both convective and stratiform upward motions remain strong through the end of the simulation, suggesting that much of the decrease seen in Fig. 12 occurs in the radial band between 150-300 km.
} 
The mean radial velocities (Fig. 11c) suggest strong boundary layer and mid-level convergence and upper-level divergence through much of the early stages of convection. With the development of convection late on the $23^{\text {rd }}$ and early on the $24^{\text {th }}$, low-level convergence and upper-level divergence increased dramatically. In addition, a layer of mid-to-upper level convergence developed in association with convection late on the $23^{\text {rd }}$ and intensified further after 12 UTC 24 July as a result of the development of stratiform precipitation. These radial velocity (divergence) profiles are similar to those reported by Montgomery et al. (2006) in their examination of a VHT pathway to tropical cyclone genesis within a parent MCV.

Relative humidities (Fig. 11d) at low to middle levels were near saturation throughout the simulation and a deep layer of near-saturated conditions existed during the initial spin up of precipitation. The trend toward weakening ascent and the transition to mean descent by 12 UTC 23 July led to a drying out of the layer above $400 \mathrm{hPa}$ during that time, although lower levels remained nearly saturated. As convection redeveloped late on the $23^{\text {rd }}$, the upper levels quickly moistened, generally at humidities that approached saturation with respect to ice.

Figure $11 \mathrm{e}$ shows the potential temperature anomaly evolution. The anomaly is defined as a perturbation with respect to the near-storm environment, determined by averaging the potential temperature within the radial band $300-350 \mathrm{~km}$. A warm anomaly is found between 800-300 hPa prior to 12 UTC 23 July, thereafter deepening to $200 \mathrm{hPa}$. The temperature anomaly becomes largest after 06 UTC 24 July between $300-200 \mathrm{hPa}$ as stratiform precipitation becomes more well developed and approximately coincides with the onset of surface pressure falls (Fig. 10). Potential temperatures at low levels remain cool throughout the simulation, with the cool layer deepening somewhat after 12 UTC 24 July. Although a warm anomaly forms near the center at low levels by 15 UTC 24 July, it is surrounded by a larger area of cooler air within the 
precipitation region. These results suggest that genesis occurs despite the maintenance of the surface cold pool. Similar results were also observed in the idealized simulations of Montgomery et al. (2006).

The potential vorticity (PV, Fig. 11f) shows a midlevel vortex centered near 600-500 hPa, with very weak PV in the upper troposphere. There is little trend in the PV time series except after 12 UTC 24 July, when PV increases as significant stratiform precipitation develops. However, although the area-averaged PV is relatively static, significant changes in PV do occur as PV is redistributed by convection, as will be shown in more detail further below. Prior to that discussion, let us first look at the mean PV within convective and stratiform regions in order to examine key characteristics in these regions. Figure 13 shows the area-averaged PV in convective and stratiform region, not weighted by area since the mean in Fig. 11f is dominated by the non-precipitating environment or anvil regions. Throughout the simulation, convective and stratiform regions exhibit specific profiles of PV. In the convective areas, PV is maximum at low levels, typically below $\sim 800 \mathrm{hPa}$, but with high $\mathrm{PV}$ extending upwards to near $400 \mathrm{hPa}$. Very low, or even negative, PV is found in the upper troposphere between 300-200 hPa. In stratiform regions, $\mathrm{PV}$ is generally maximum at middle levels around $500 \mathrm{hPa}$, with higher values extending down to near the surface and very low values in the upper troposphere. Examination of animations of the PV field suggests that some of the higher PV air at low levels in the stratiform region originated within convective regions. The results in Figs. 12 and 13 support the work of Tory et al. (2006a, 2006b) in that they indicate that the stratiform precipitation regions primarily enhance PV at mid levels. Without deep convection, convergence is limited to mid levels while divergence occurs at low levels, which does not favor PV 
enhancement near the surface. As in Tory et al. (2006a), deep convection favors PV enhancement at low to mid levels, suggesting that genesis cannot begin without deep convection.

The convectively generated PV at low levels has a large impact on the pressure and wind fields. Figure 14 shows plots of smoothed ${ }^{3} 850 \mathrm{hPa}$ PV and sea-level pressure for selected times. At 12 UTC 23 July (Fig. 14a), even though there was relatively little deep convection at this time (see Fig. 12a), there were some isolated areas of intense convection, the most prominent being near the center of the storm in the sea-level pressure field. A local core of very intense PV (labeled P1) was associated with this convection and had just moved into the Bay of Campeche from the Yucatan Peninsula. Pressure perturbations associated with this intense PV feature added to the pressure deficit present on larger scales so that the pressure minimum was collocated with P1. Six hours later (Fig. 14b), P1 had moved west-northwestward and continued to be collocated with the minimum pressure. By 00 UTC 24 July (Fig. 14c), the PV maximum P1 was still present, a good $12 \mathrm{~h}$ after its formation, and continued to be associated with the minimum pressure. A second intense PV feature (labeled P2) formed to the northwest of P1. Over the next four hours (Fig. 14d), P1 weakened. From this point on, although the original PV maximum weakened, the pressure minimum associated with P1 remained intact and new intense PV anomalies continually formed, dissipated, or merged with this PV maximum so that a PV feature tracking with P1 was present through the end of the simulation. It is for this reason that we continue to label this feature P1. P2 moved southward to the west of P1 during this time. By 08 UTC 24 July (Fig. 14e), convective activity was nearing its peak and multiple convective-scale PV anomalies had formed. P1 remained weak, but associated with a pressure minimum. P2

\footnotetext{
${ }^{3}$ The PV fields were smoothed using 10 passes of a 9-point-weighted smoother [Eq. 11-107 of Haltiner and Williams (1980)] to make the plots more legible, so PV features appear larger than their original, unfiltered size.
} 
moved southward and was collocated with a second pressure minimum. A third intense PV anomaly (labeled P3) formed a third pressure minimum. By 12 UTC (Fig. 14f), P2 and P3 had moved very close to each other and merged by 18 UTC (Fig. 14g). After this time, similar to P1, the pressure minimum associated with the merged P2-P3 PV maximum remained intact (labeled P2-3, Figs. 14g, h), with multiple convective-scale PV anomalies forming, merging, and growing following the two distinct pressure minima (i.e., P1 and P2-3).

The formation and coalescence of the convectively generated PV anomalies into mesoscale PV features, and their relationship to the low-level circulation is illustrated in Fig. 15. Beginning at 06 UTC 24 July (Fig. 15a), convection had just become more intense and widespread and the three PV features P1, P2, and P3 were apparent in the PV fields. The lowlevel flow had just formed a closed cyclonic circulation, with the PV anomalies along the inner edge of the stronger cyclonic flow. By 12 UTC (Fig. 15b), the number of PV anomalies increased and mergers had begun. The circulation was now centered on anomalies P2 and P3. Over the next six hours (Fig. 15c), convective-scale PV anomalies continued to form and coalesce into two growing regions of high PV, both appearing to contribute equally to the lowlevel circulation. Finally, by the end of the simulation, 00 UTC 25 July (Fig. 15d), the PV had coalesced into two very distinct mesoscale regions of high PV, with the circulation center collocated with P1.

At mid levels (500 hPa, Fig. 16), a similar evolution occurred. At 06 UTC 24 July (Fig. 16a), several intense PV anomalies were dispersed across the region. The flow showed strong cyclonic curvature, but was not closed at this time in a ground-relative reference frame (a closed circulation in a wave-relative reference frame would be centered near grid point $x=180, y=200$ ). By 12 UTC (Fig. 16b), the number of intense PV features increased, with some features already 
indicating mergers, similar to lower levels at this time. Six hours later (Fig. 16c), significant merger of PV occurred and a strong closed cyclonic circulation had formed. This pattern was then maintained for the remaining 6 hours of the simulation. As implied by Fig. 13, both convective and stratiform processes likely played a role in this intensification and consolidation of PV, with stratiform processes likely dominant after 15 UTC 24 July.

\section{The I2112 Simulation}

The simulation initialized at 06 UTC 22 July produced a storm evolution that best compared to the available observations (Quikscat winds, TRMM precipitation, dropsondes), although it led to sea-level pressures that were generally weaker than observed. Because of the weak background vortex, the merger of convectively generated PV anomalies occurred relatively slowly and primarily in the last $12 \mathrm{~h}$ of the simulation. In the interest of knowing how the evolution might change if the background vortex were stronger, a simulation initialized at 12 UTC 21 July is described in this section because it produced a stronger vortex when the system was east of the Yucatan Peninsula. While the evolution of the storm is basically similar to the I2206 run, there are some key differences that will be highlighted here.

The evolution of the simulated reflectivity and winds at $500 \mathrm{~m}$ is shown in Fig. 17, with particular emphasis given to the development of the system to the east of the Yucatan Peninsula. At 00 UTC 22 July (Fig. 17a), a broad region of convection extended from the northeast coast of Honduras to the Yucatan in a region where the winds showed weak cyclonic curvature. Six hours later (Fig. 17b), one line of convection paralleled the Honduran coastline while another paralleled the Yucatan coastline. In the southwestern portion of the first line, the flow exhibited strong cyclonic curvature as the low-level PV increased. By 12 UTC 22 July (Fig. 17c), a prominent vortex formed in association with convection on the coast of Belize while another 
region of convection extended eastward from the northeastern coast of the Yucatan. This pattern is very similar to a TRMM image near this time and the location of a PV maximum analyzed by NCEP (K. Mallen, personal communication). By midday on July 23 (Fig. 17d), the system had crossed over the Yucatan and entered the Bay of Campeche. The circulation was located further north and appeared to be stronger than that indicated by Quikscat (Fig. 4b) and the convection more active than that suggested by GOES satellite imagery (not shown). By 06 UTC 24 July (Fig. 17e), stronger convection developed, consistent with the observations and with the I2206 simulation. The storm continued its movement northwestward, making landfall around 00 UTC 25 July about $1.4^{\circ}$ latitude too far north.

The formation of the initial vortex and its subsequent evolution are examined, as in Fig. 11, through time series of the vertical profiles of various quantities within a radius of $300 \mathrm{~km}$. The area-averaged vertical motion (Fig. 18a) shows the development of very strong convection during the first $24 \mathrm{~h}$ of the simulation in association with the systems on the eastern side of the Yucatan Peninsula. A breakdown of this vertical motion into its convective and stratiform components (Figs. 19a, b) indicates strong and deep convection through the first $15 \mathrm{~h}$ of simulation, with shallower or fewer deep cells thereafter through midday on July 23. Stratiform vertical motion developed quickly and peaked just after 00 UTC 22 July (Fig. 19b), gradually diminishing by 00 UTC 23 July as deep convection over the broader region subsided, although it continued locally near the storm core.

As with the I2206 simulation, identification of a center location was difficult until midday on July 22. As a result, the center location was determined subjectively based upon the convection at earliest stages and later on was based on the $850-\mathrm{hPa}$ geopotential heights as the vortex developed. Consequently, during the first $24 \mathrm{~h}$ of simulation, the tangential and radial 
velocity fields must be viewed with caution. The results in Fig. 18b and 18c suggest very deep inflow and convergence up to $\sim 400 \mathrm{hPa}$, with strong divergence above, and the rapid development of deep cyclonic flow by 12 UTC 22 July (see also the PV field in Fig. 18f). With the weakening of convection on July 23 , the vortex became somewhat weaker and shallower and the inflow was confined mostly to very low levels. The development on July 24 was very similar to the I2206 case, with slow strengthening and deepening of the vortex, peak inflow at lower levels, a second peak at mid to upper levels, and strong outflow at upper levels.

The relative humidity field (Fig. 18d) shows a deep layer of saturation during the first 24 h, a period of mid-to-upper level drying during July 23 when there was stronger mean subsidence in the environment (not shown), and then a return to nearly saturated conditions on July 24 . The evolution of the warm anomaly is shown in Fig. 18e and shows strong mid-to-upper level warming and low-level cooling during the first $24 \mathrm{~h}$, followed by a gradual lowering of the warm anomaly and reduction of the depth of the cool air at low levels during July 23. With redevelopment of convection on July 24 , a double-peaked structure emerged in the temperature anomaly field, with maximum warm anomalies at lower and upper levels near the levels of peak upward motion in convective regions (Fig. 19a).

The PV field (Fig. 18f) shows the development of a deep layer of PV that is maximum around 600-500 hPa around 18 UTC 22 July. When the PV is examined separately in convective and stratiform regions (Figs. 19c, d), the results again show significant PV at low levels in convective regions and stronger PV at mid levels in stratiform regions. Some of the high PV above $600 \mathrm{hPa}$ in convective regions between 00 UTC 22 July and 00 UTC 23 July may result from convection developing within stratiform areas already possessing high midlevel PV, while stratiform areas with high low-level PV may contain some PV originally associated with 
convection. In general, though, convective regions play a large role in generating low-level PV while stratiform regions enhance mid-level PV.

The relationship between the PV anomalies and the flow at $850 \mathrm{hPa}$ and $500 \mathrm{hPa}$ are shown in Figs. 20 and 21, respectively. At $850 \mathrm{hPa}$, scattered and more isolated PV anomalies at 06 UTC 22 July (Fig. 20a) quickly merged to form a larger, more intense PV anomaly at 12 UTC 22 July at the Belize coast (Fig. 20b), with a strong cyclonic circulation. Animations of PV show that this strong PV anomaly persisted for $\sim 24 \mathrm{~h}$, maintaining itself through merger with nearby weaker convectively generated PV. Its presence and its merger with these convective PV anomalies is evident in the high area-averaged PV seen in Fig. 19c. By 12 UTC 23 July (Fig. 20c), the low-level PV was characterized by a few areas of intense PV associated with convection as well as with high PV located in non-precipitating areas, but generated within earlier convection. As convective activity increased around 00 UTC 24 July (cf. Fig. 19a, 20d), new convective-scale regions of high PV were forming and merging with pre-existing high PV. Over the next 18 hours (Figs. 20e,f), the merger of these convectively generated PV anomalies led to the gradual intensification and growth of the vortex.

At $500 \mathrm{hPa}$, early stages (Fig. 21a, b) were characterized by widely scattered regions of high PV located primarily in stratiform and non-precipitating anvil regions, with small contributions from convection. At 12 UTC 23 July (Fig. 21c), with the decrease in both convective and stratiform vertical motions (Figs. 19a, b), the number and area of intense PV features decreased. The flow was predominantly southerly to the east of the high-PV region and easterly within the high-PV region of the southern Gulf of Mexico, with no closed circulation found within the domain. As convection increased by 00 UTC 24 July (Fig. 21d) and continued through the end of the simulation (Figs. 19, 21e, and 21f), new regions of high PV formed within 
both convective and stratiform areas, gradually merging after 06 UTC 24 July to form a mesoscale region of high PV. At 00 UTC 24 July, the mid-level flow was predominantly southerly to southeasterly within and to the east of the high-PV region, but after the rapid mergers of PV after 06 UTC (Figs. 21e, f), the flow very rapidly developed a closed circulation. During July 24 (Figs. 21d-f), the 500 hPa high PV was generally located north and west of the 850-hPa high PV, suggesting that the cyclonic flow at $850 \mathrm{hPa}$ was primarily associated with the 850-hPa PV rather than a downward projection of the mid-level PV. Since the 850-hPa high PV was generated primarily by deep convection, the results suggest that VHTs played a key, if not primary, role in the spin up of the low-level flow.

\section{Discussion}

Several hypotheses have been put forward for the mechanism(s) of generation of surface circulation associated with tropical cyclones. This study makes use of results from two numerical simulations of the genesis of Tropical Storm Gert (2005) to investigate the development of lowlevel circulation and its relationship to the precipitation evolution. The roles of convective and stratiform precipitation processes within the mesoscale precipitation system that formed Gert are discussed.

The nearly constant high values of relative humidity below $500 \mathrm{hPa}$ and the nearly simultaneous increases in the lower and mid-level tangential flows suggest a different development of the low-level vortex than was presented by Bister and Emanuel (1997). In their conceptual model, the precursor to genesis (development of the surface vortex) is a mesoscale region of stratiform precipitation with relatively dry conditions at lower to mid-levels in a mesoscale downdraft. The vortex lowers to the surface as evaporation of the precipitation gradually moistens the lower layers and the peak in the evaporative cooling profile nears the 
surface. Once the lower layer is moistened, cold downdrafts are decreased or eliminated, surface latent and sensible heat fluxes increase, and subsequent convection readily increases the lowlevel circulation. In the Gert simulations, there is no precursor mesoscale region of stratiform precipitation. Lower to mid-levels are already quite moist. In the I2206 simulation, a deep layer of cyclonic tangential winds are present from the onset of the simulation and are strongest at the top of the boundary layer rather than at midlevels. Surface winds are such that the WISHE process is active throughout the simulation. As a result, convection is immediately able to spin up the circulation at lower to middle levels. This fact is evident from Figs. 11b and 12a in the increases in mean tangential winds coincident with the onset of significant convective activity. As stratiform precipitation develops, it enhances mid-level inflow and convergence, thereby producing increases in the mid-level tangential winds. If the Bister and Emanuel process played a role in the development of Gert, it must have done so prior to the initial time of the I2206 simulation. The I2112 simulation starts with a weak mid-level vortex and very moist conditions. The immediate onset of deep convection rapidly spins up both the lower and mid-level tangential winds, with peak winds near the top of the boundary layer. Since the vortex is moist at the beginning of this simulation, the Bister and Emanual mechanism was not active in this simulation, but may have been active at an earlier time, if at all.

Ritchie and Holland (1997) and Simpson et al. (1997) suggested that merger of midlevel mesoscale vortices associated with the stratiform precipitation regions of multiple MCSs can enlarge the scale of the merged vortex in both the horizontal and vertical extent, eventually leading to formation of a surface circulation. While such a process can undoubtedly play a role in some events, in neither the Gert observations nor the simulation is there evidence of merger of mid-level mesoscale vortices induced by multiple MCSs. Instead, the merger process is 
associated with both low- and mid-level smaller-scale vortices within an MCS, with convectivescale processes playing a major role in PV concentration and merger.

Nolan (2007) used high-resolution WRF simulations initialized with idealized vortices to examine triggers for tropical cyclogenesis. He found that the inner-core region becomes humidified by moist detrainment from deep convection and once the core relative humidity exceeds $80 \%$ over most of the depth of the troposphere, the mid-level vortex contracts and intensifies. When the mid-level vortex reaches sufficient strength and the inner core is nearly saturated, a smaller-scale vortex forms very rapidly near the surface in association with a VHT and becomes the core of an intensifying cyclone. In the Gert simulation, the onset of intensification on July 23 occurs with the development of deep convection on that day. Prior to this convection, relative humidity above $\sim 500 \mathrm{hPa}$ is at a minimum midday on 23 July. Relative humidity above $500 \mathrm{mb}$ increases rapidly with the onset of deep convection in the later part of 23 July, thus meeting one of the requirements described by Nolan (2007). However, in the simulated Gert, intensification of the low-level vortex is concurrent with, if not prior to, intensification of the mid-level vortex and the storm never reaches a point of rapid intensification as seen in Nolan's idealized cases. The differences between the evolution of Gert and Nolan's idealized simulations may lie in some aspect of the more complicated environment of Gert that is not included in the idealized initial environment but that more readily facilitates spin-up at low levels.

The evolution of the low-level potential vorticity field in the Gert simulations is very similar to that seen in idealized simulations by Van Sang et al. (2008). In their experiments, storm intensification begins with the development of a ring of convection that produces intense small-scale vorticity dipoles, with strong cyclonic vorticity and weak anticyclonic vorticity. Over 
time, the cyclonic vorticity anomalies move inward while the negative vorticity anomalies move outward, ultimately leading to merger of the cyclonic vortices and axisymmetrization of the anticyclonic vorticity. As a result, the VHTs contribute directly to the storm-scale spin up. The evolution of the 850-hPa PV field shown in Fig. 14 shows the same basic pattern of gradual concentration of cyclonic PV in the inner region of the storm and expulsion of anticyclonic PV to outer regions, particularly after convection develops on 24 July. These results confirm the findings of Hendricks et al. (2004), Montgomery et al. (2006), and Van Sang et al. (2008) that VHTs play a key, if not leading, role in intensifying low-level circulation during tropical cyclogenesis.

\section{Conclusions.}

This paper examines high-resolution simulations of Tropical Storm Gert (2005), which formed in the Gulf of Mexico during NASA's Tropical Cloud Systems and Processes Experiment. Simulations are conducted using the Weather Research and Forecasting numerical prediction model and results are thoroughly validated against satellite and airborne data sets. Two simulations are examined; one that better matches available observations but underpredicts the storm's minimum sea-level pressure and a second one that somewhat over-intensifies the storm, but provides a set of simulations that encapsulates the overall genesis and development characteristics of the observed storm.

A convective-stratiform precipitation separation technique was applied to investigate the roles of convective and stratiform precipitation processes in the development of Gert. As is typical for convective systems (Houze 1993), convective system evolution was characterized by intense and deep convective upward motions followed by increasing stratiform-type vertical motions (upper-level ascent, low-level descent). Potential vorticity in convective regions was 
strongest at low levels, but with high PV extending up to almost $300 \mathrm{hPa}$. Stratiform region PV was strongest at mid levels. Given the evolution of convective and stratiform regions mentioned above, this result suggests that convective processes act to spin up lower levels prior to the spin up of middle levels by stratiform processes. After convection subsides, stratiform processes continue to spin up middle levels for some period of time. Subsequent convective systems occurring in the higher PV wake of the previous one would also act to enhance PV at low levels via convection prior to enhancing mid-level PV via stratiform processes. This process was seen in the case of Gert with the two primary episodes of convective system development on July 22 and then beginning late on July 23.

Intense VHTs were prominent features of the low-level cyclonic vorticity field. The most prominent PV anomalies persisted more than $6 \mathrm{~h}$ and often were associated with localized minima in the sea-level pressure field. A gradual segregation of the PV occurred, with cyclonic PV moving inward and anticyclonic PV moving outward from the storm center. In the case of the weaker storm development (the I2206 experiment), two intense PV regions dominated the flow, forming two storm centers, each gradually intensifying as they merged with newer VHTs. In the case of the stronger surface pressure development (the I2112 experiment), the VHTs merged into a single low pressure center, gradually increasing the mean vorticity near the center. As pointed out by Montgomery et al. (2006), not only do these hot towers act to locally increase the vorticity, they also contribute to the evolution of the system-scale mean secondary circulation, increasing the low- and mid-level inflow, and converging the background cyclonic vorticity and the convective-scale cyclonic vorticity generated by the hot towers.

Nearly concurrently with this VHT-induced development, stratiform precipitation processes strongly enhanced the mean inflow and convergence at middle levels, rapidly 
increasing the mid-level vorticity. However, the stratiform vertical motion profile is such that while it increases mid-level vorticity, it decreases vorticity near the surface as a result of lowlevel divergence. Consequently, the results presented here for Gert are in agreement with Tory et al. (2006a, 2006b) in that while stratiform precipitation regions may significantly increase cyclonic circulation at mid-levels, convective vortex enhancement at low to mid-levels is likely necessary for genesis.

Acknowledgments: This work was supported by Dr. Ramesh Kakar at NASA Headquarters with

funds from the NASA TCSP program. M. T. Montgomery was supported through MultiInteragency Procurement Request \#NNG07HU17I. K. Mallen was supported through a fellowship from the Center for Earth-Atmosphere Studies, a cooperative agreement between NASA and CSU. The simulations were conducted on NASA Center for Computational Sciences facilities.

\section{References}

Bister, M. and K. A. Emanuel, 1997: The genesis of Hurricane Guillermo: TEXMEX analysis and a modeling study. Mon. Wea, Rev., 125, 2662-2682.

Brandes, E. A, and C. L. Ziegler, 1993: Mesoscale downdraft influences on vertical vorticity in a mature mesoscale convective system. Mon. Wea. Rev., 121, 1337-1353.

Braun, S. A., 2002: A cloud-resolving simulation of Hurricane Bob (1991): Storm structure and eyewall buoyancy. Mon. Wea. Rev., 130, 1573-1592.

Braun, S. A., M. T. Montgomery, and Z. Pu, 2006: High-Resolution Simulation of Hurricane Bonnie (1998). Part I: The Organization of Vertical Motion. J. Atmos. Sci., 63, 19-42. 
Chen, F., and J. Dudhia, 2001: Coupling an advanced land-surface/ hydrology model with the Penn State/ NCAR MM5 modeling system. Part I: Model description and implementation. Mon. Wea. Rev., 129, 569-585.

Chen, S. S, and W. M. Frank, 1993: A numerical study of the genesis of extratropical convective mesovortices. Part I: Evolution and Dynamics. J. Atmos. Sci., 50, 2401-2426.

Chong, M., and O. Bousquet, 1999: A mesovortex within a near-equatorial mesoscale convective system during TOGA-COARE. Mon. Wea. Rev., 127, 1145-1156.

Dudhia, J., 1989: Numerical study of convection observed during the winter monsoon experiment using a mesoscale two-dimensional model, J. Atmos. Sci., 46, 3077-3107.

Dunkerton, T. J., M. T. Montgomery, and Z. Wang, 2008: Tropical cyclogenesis in a tropical wave critical layer: Easterly waves. Atmospheric Chemistry and Physics, accepted.

Emanuel K. A., 1986: An air-sea interaction theory for tropical cyclones. Part I: Steady-state maintenance. J. Atmos. Sci, 43, 585-604.

Emanuel, K. A., 1987: An air-sea interaction model of intraseasonal oscillations in the tropics. $J$. Atmos. Sci., 44, 2324-2340.

Gamache, J. F., and R. A. Houze, Jr., 1982: Mesoscale air motions associated with a tropical squall line. Mon. Wea. Rev., 110, 118-135.

Gray, W. M. 1975: Tropical cyclone genesis. Dept. of Atmos. Sci. Paper No. 234, Colo. State University, Ft. Collins, CO, 121 pp.

Gray, W.M. (1979): Hurricanes: Their formation, structure and likely role in the tropical circulation. Meteorology Over Tropical Oceans. D. B. Shaw (Ed.), Roy. Meteor. Soc., James Glaisher House, Grenville Place, Bracknell, Berkshire, RG12 1BX, pp.155-218. 1998: The formation of tropical cyclones. Meteor. Atmos. Phys., 67, 37-69. 
Haltiner, G. J., and R. T. Williams, 1980. Numerical Prediction and Dynamic Meteorology. $2^{\text {nd }}$ Ed. John Wiley and Sons, 477 pp.

Halverson, J., P. L. Azofeifa, M. Black, S. Braun, D. Cecil, M. Goodman, A. Heymsfield, G. Heymsfield, R. Hood, T. Krishnamurti, G. McFarquhar, J. Molinari, R. Rogers, J. Turk, C. Velden, D.-L. Zhang, E. Zipser, R. Kakar, 2007: NASA's Tropical Cloud Systems and Processes (TCSP) Experiment: Investigating Tropical Cyclogenesis and Hurricane Intensity Change. Bull. Amer. Meteor. Soc., 88, 867-882.

Hendricks, E. A., M. T. Montgomery, and C. A. Davis, 2004: The role of "vortical" hot towers in the formation of Tropical Cyclone Diana (1984). J. Atmos. Sci., 61, 1209-1232.

Hong, S.-Y., J. Dudhia, and S.-H. Chen, 2004: A Revised Approach to Ice Microphysical Processes for the Bulk Parameterization of Clouds and Precipitation, Mon. Wea. Rev., 132, $103-120$.

Hong, S.-Y., Y. Noh, and J. Dudhia, 2006: A new vertical diffusion package with an explicit treatment of entrainment processes. Mon. Wea. Rev., 134, 2318-2341.

Houze, R. A., Jr., 1993: Cloud Dynamics. Academic Press, San Diego, 573 pp.

Janjic, Z. I., 1990: The step-mountain coordinate: physical package, Mon. Wea. Rev., 118, $1429-1443$.

Janjic, Z. I., 1996: The surface layer in the NCEP Eta Model, Eleventh Conference on Numerical Weather Prediction, Norfolk, VA, 19-23 August; Amer. Meteor. Soc., Boston, MA, 354355.

Janjic, Z. I., 2002: Nonsingular Implementation of the Mellor-Yamada Level 2.5 Scheme in the NCEP Meso model, NCEP Office Note, No. 437, 61 pp. 
Kain, J. S., and J. M. Fritsch, 1990: A one-dimensional entraining/ detraining plume model and its application in convective parameterization, J. Atmos. Sci., 47, 2784-2802.

Kain, J. S., and J. M. Fritsch, 1993: Convective parameterization for mesoscale models: The Kain-Fritcsh scheme, The representation of cumulus convection in numerical models, K. A. Emanuel and D.J. Raymond, Eds., Amer. Meteor. Soc., 246 pp.

Mlawer, E. J., S. J. Taubman, P. D. Brown, M. J. Iacono, and S. A. Clough, 1997: Radiative transfer for inhomogeneous atmosphere: RRTM, a validated correlated-k model for the longwave. J. Geophys. Res., 102 (D14), 16663-16682.

Montgomery, M. T., M. E. Nicholls, T. A. Cram, and A. Saunders, 2006: A "vortical" hot tower route to tropical cyclogenesis. J. Atmos. Sci., 63, 355-386.

Noh, Y., W. G. Cheon, S. Y. Hong, and S Raasch, 2003: Improvement of the K-profile model for the planetary boundary layer based on large eddy simulation data. Boundary-Layer Meteor., 107, 401-427.

Nolan, D. S., 2007: What is the trigger for tropical cyclogenesis? Aust. Met. Mag., 56, 241-266.

Portabella, M., and A. Stoffelen, 2001: Rain detection and quality control of SeaWinds. J. of Atmos. Oceanic Tech., 18, 1171-1183.

Ritchie, E. A., and G. J. Holland, 1997: Scale interactions during the formation of Typhoon Irving. Mon. Wea. Rev., 125, 1377-1396.

Rodgers, E., W. Olson, J. Halverson, J. Simpson, and H. Pierce, 1994: Environmental forcing of Supertyphoon Paka's (1997) latent heat structure.

Roundy, P. E., and W. M. Frank, 2004: A climatology of waves in the Equatorial region. $J$. Atmos. Sci., 61, 2105-2132. 
Simpson, J., E. A. Ritchie, G. J. Holland, J. Halverson, and S. Stewart, 1997: Mesoscale interactions in tropical cyclone genesis. Mon. Wea. Rev., 125, 2643-2661.

Skamarock, W. C., J. B. Klemp, J. Dudhia, D. O. Gill, D. M. Barker, W. Wang and J. G. Powers, 2005: A description of the advanced research WRF version 2. NCAR Technical Note $468+S T R, 88 \mathrm{pp}$.

Steranka, J., E. B. Rodgers, and R. C. Gentry, 1986: The relationship between satellite measured convection burst and tropical cyclone intensification. Mon. Wea. Rev., 114, 1539-1546.

Tao, W.-K., J. Simpson, C.-H. Sui, B. Ferrier, S. Lang, J. Scala, M.-D. Chou, and K. Pickering, 1993: Heating, moisture, and water budgets of tropical and midlatitude squall lines: Comparisons and sensitivity to longwave radiation. J. Atmos. Sci., 50, 673-690.

Tory, K.J., Montgomery, M.T. and Davidson, N.E. 2006a. Prediction and diagnosis of tropical cyclone formation in an NWP system. Part I: The critical role of vortex enhancement in deep convection. J. Atmos. Sci., 63, 3077-3090.

Tory, K.J., Montgomery, M.T., Davidson, N.E. and Kepert, J.D. 2006b. Prediction and diagnosis of tropical cyclone formation in an NWP system. Part II: A diagnosis of tropical cyclone Chris formation. J. Atmos. Sci., 63, 3091-3113.

Van Sang, N., R. K. Smith, and M. T. Montgomery, 2008: Tropical-cyclone intensification and predictability in three dimensions. Q. J. R. Meteorol. Soc., 134, 563-582.

Velasco, I., and J. M. Fritsch, 1987: Mesoscale convective complexes in the Americas. J. Geophys. Res., 92, 9591-9613.

Verlinde J., and W. R. Cotton, 1990: A mesovortex couplet in the trailing anvil region of a multicellular convective complex. Mon. Wea. Rev., 118, 993-1010. 
Yu, C.-K., B. J.-D. Jou, and B. F. Smull, 1999: Formative stage of a long-lived mesoscale vortex observed by airborne Doppler radar. Mon. Wea. Rev., 127, 838-857.

Zehr, R. 1992. Tropical cyclogenesis in the Western North Pacific. NOAA Tech. Rep., NESDIS 61, $181 \mathrm{pp}$.

Zhang, D.-L., and R. A. Anthes, 1982: A high-resolution model of the planetary boundary layer-Sensitivity tests and comparisons with SESAME-79 data. J. Appl. Meteor., 21, 15941609. 
Table 1. Description of aircraft flights during the formation of Gert

\begin{tabular}{|l|l|l|l|l|}
\hline Aircraft & Date & Takeoff time & Landing time & Description \\
\hline $\begin{array}{l}\text { ER-2 } \\
\text { NOAA43 }\end{array}$ & July 23 & $\begin{array}{l}\text { 0208 UTC } \\
\text { 0003 UTC }\end{array}$ & $\begin{array}{l}\text { 1015 UTC } \\
\text { 0820 UTC }\end{array}$ & $\begin{array}{l}\text { Genesis mission surveilling } \\
\text { wave around the Yucatan }\end{array}$ \\
\hline NOAA42 & July 23 & $\begin{array}{l}\text { 1606 UTC July } \\
23\end{array}$ & $\begin{array}{l}\text { 0110 UTC July } \\
24\end{array}$ & $\begin{array}{l}\text { Solo P3 mission sampling wave } \\
\text { around the Yucatan }\end{array}$ \\
\hline $\begin{array}{l}\text { ER-2 } \\
\text { NOAA43 }\end{array}$ & July 24 & $\begin{array}{l}0159 \text { UTC } \\
\text { 0024 UTC }\end{array}$ & $\begin{array}{l}\text { 1000 UTC } \\
\text { 0928 UTC }\end{array}$ & $\begin{array}{l}\text { Mission sampling early genesis } \\
\text { stage and formation of deep } \\
\text { convection }\end{array}$ \\
\hline NOAA43 & July 24 & $\begin{array}{l}1648 \text { UTC July } \\
24\end{array}$ & $\begin{array}{l}0117 \text { UTC July } \\
25\end{array}$ & $\begin{array}{l}\text { Solo P3 mission surveying } \\
\text { continuing genesis stage prior } \\
\text { to landfall }\end{array}$ \\
\hline ER-2 & July 25 & 0200 UTC & 1013 UTC & Solo ER-2 flight after landfall \\
\hline
\end{tabular}




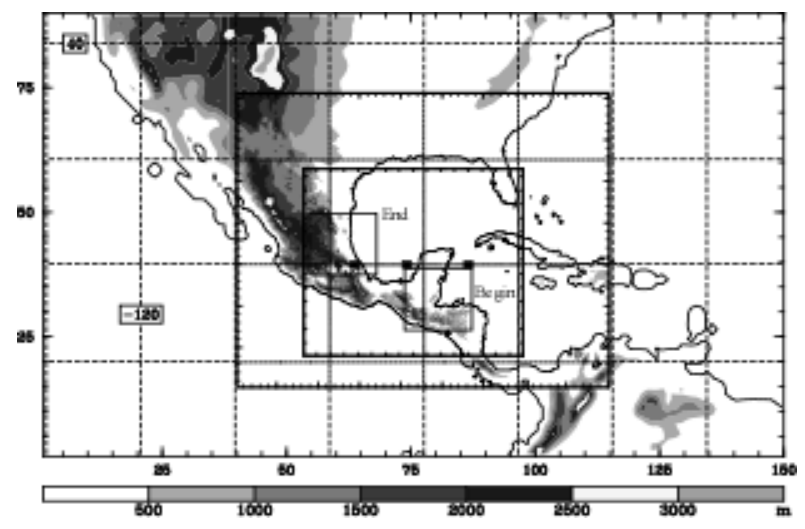

Figure 1. Model domains, with shading indicated topography. Nested grids are shown and correspond to the 18-, 6-, and 2-km grids. The initial and final positions of the 2-km grid are indicated. 

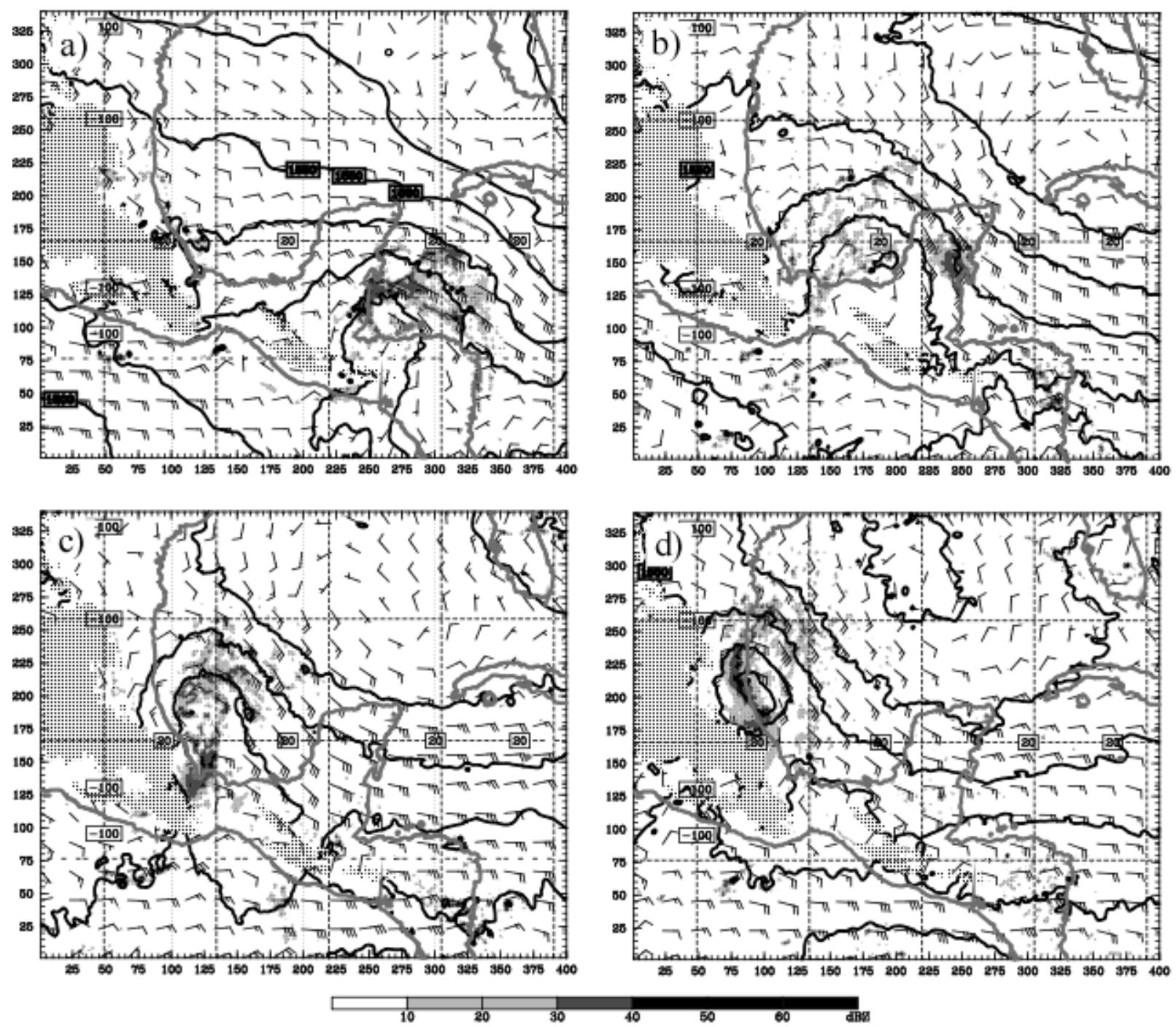

Figure 2. Geopotential height (contours, $12.5 \mathrm{~m}$ intervals), simulated radar reflectivity (shading), and wind barbs from the 6-km domain at $850 \mathrm{hPa}$ at (a) 12 UTC $22 \mathrm{July}$, (b) 12 UTC $23 \mathrm{July}$, (c) 06 UTC 24 July, and (d) 18 UTC 24 July. Gray bold lines indicate coastlines. Stippled regions indicate where the $850-\mathrm{hPa}$ surface intersects terrain. 
a) 12 UTC 22 July

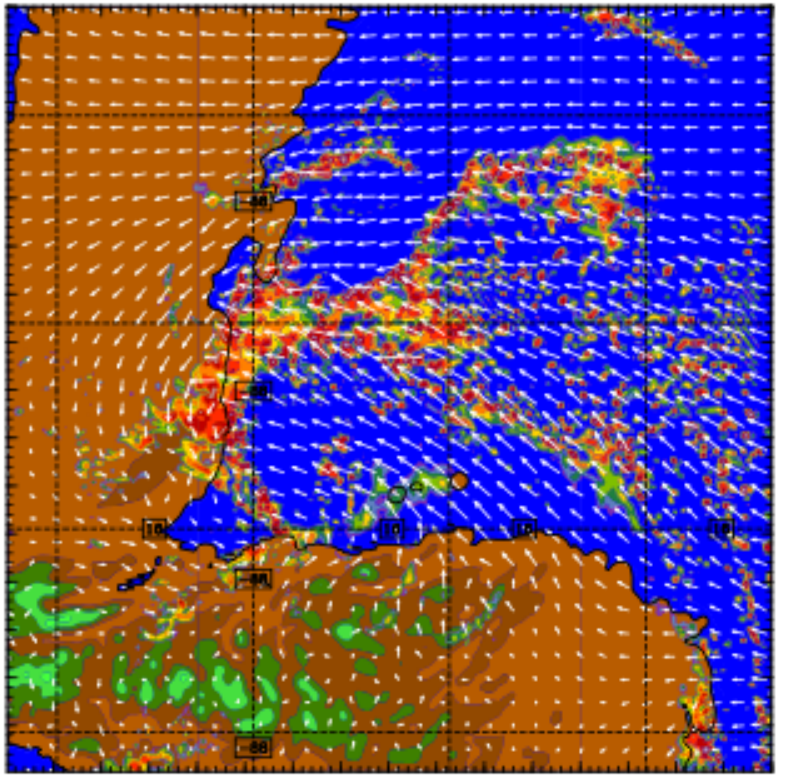

c) 12 UTC 23 July

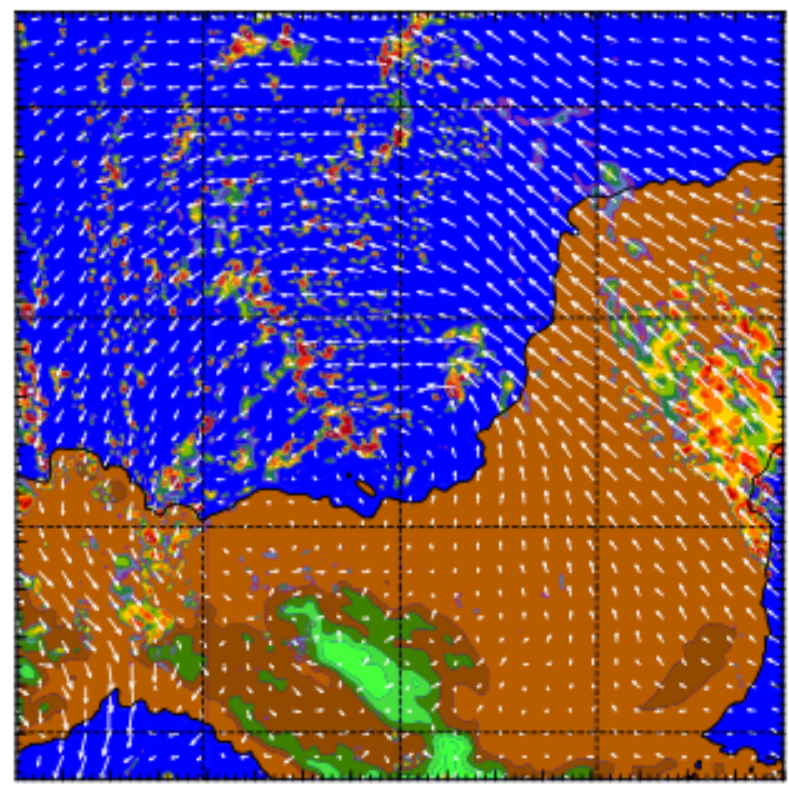

b) 18 UTC 22 July

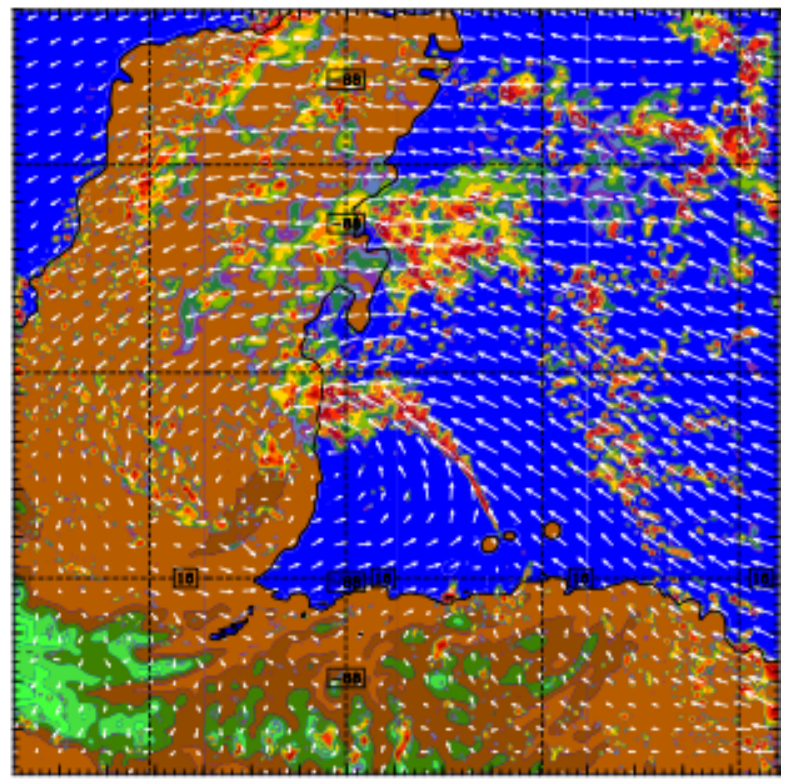

d) 18 UTC 23 July

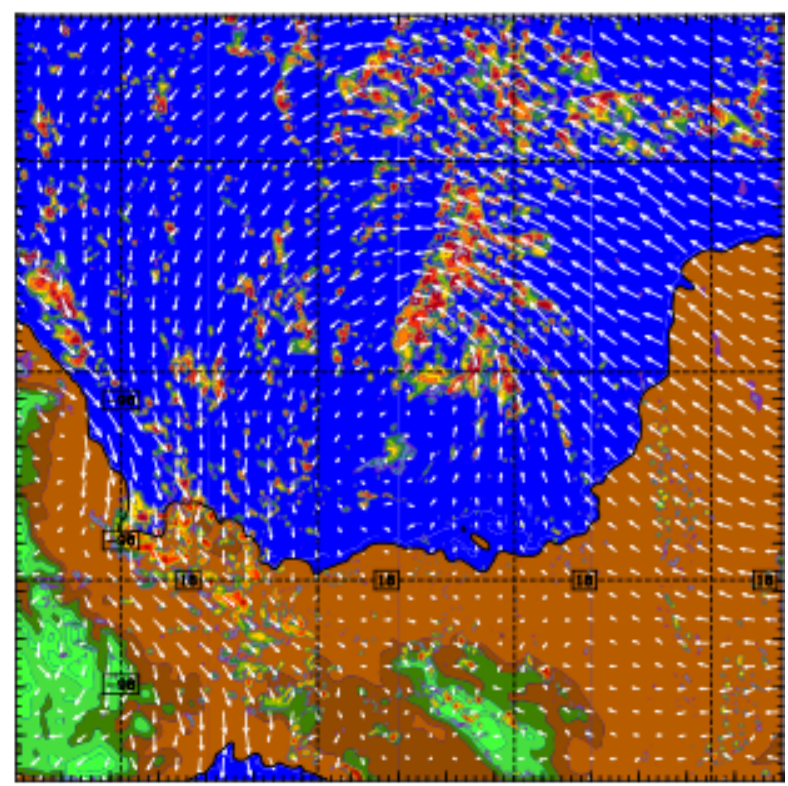

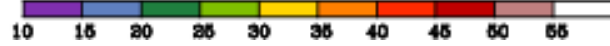

Figure 3. Simulated radar reflectivity and winds at $500 \mathrm{~m}$ altitude for the I2206 simulation. Land and ocean regions are indicated by brown and blue shading, respectively. Latitude and longitude lines are drawn every $2^{\circ}$. 
e) 00 UTC 24 July

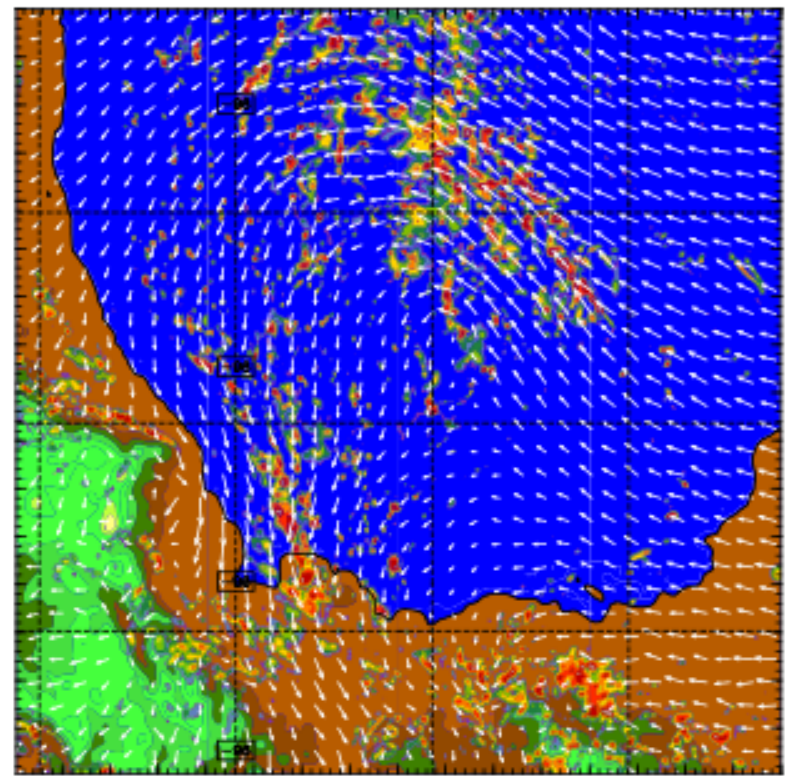

g) 12 UTC 24 July

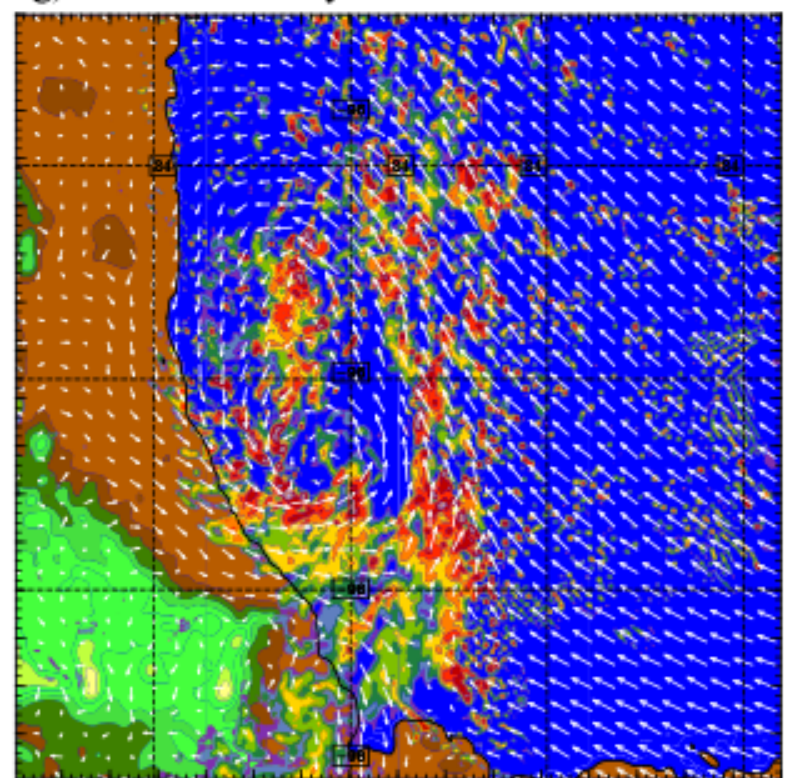

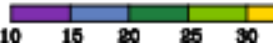

f) 06 UTC 24 July

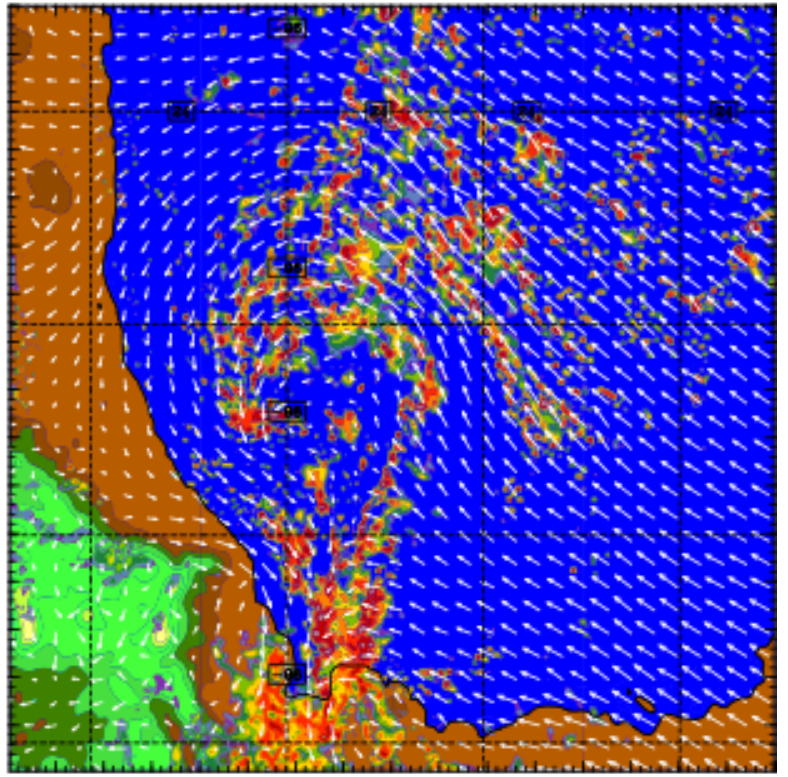

h) 18 UTC 24 July

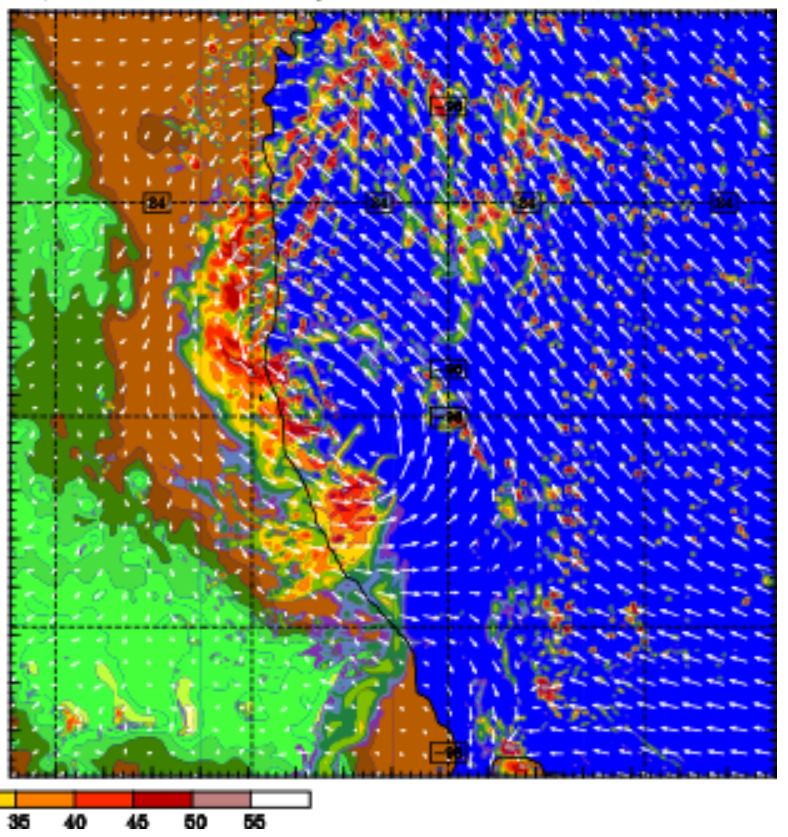

Figure 3 (continued). 

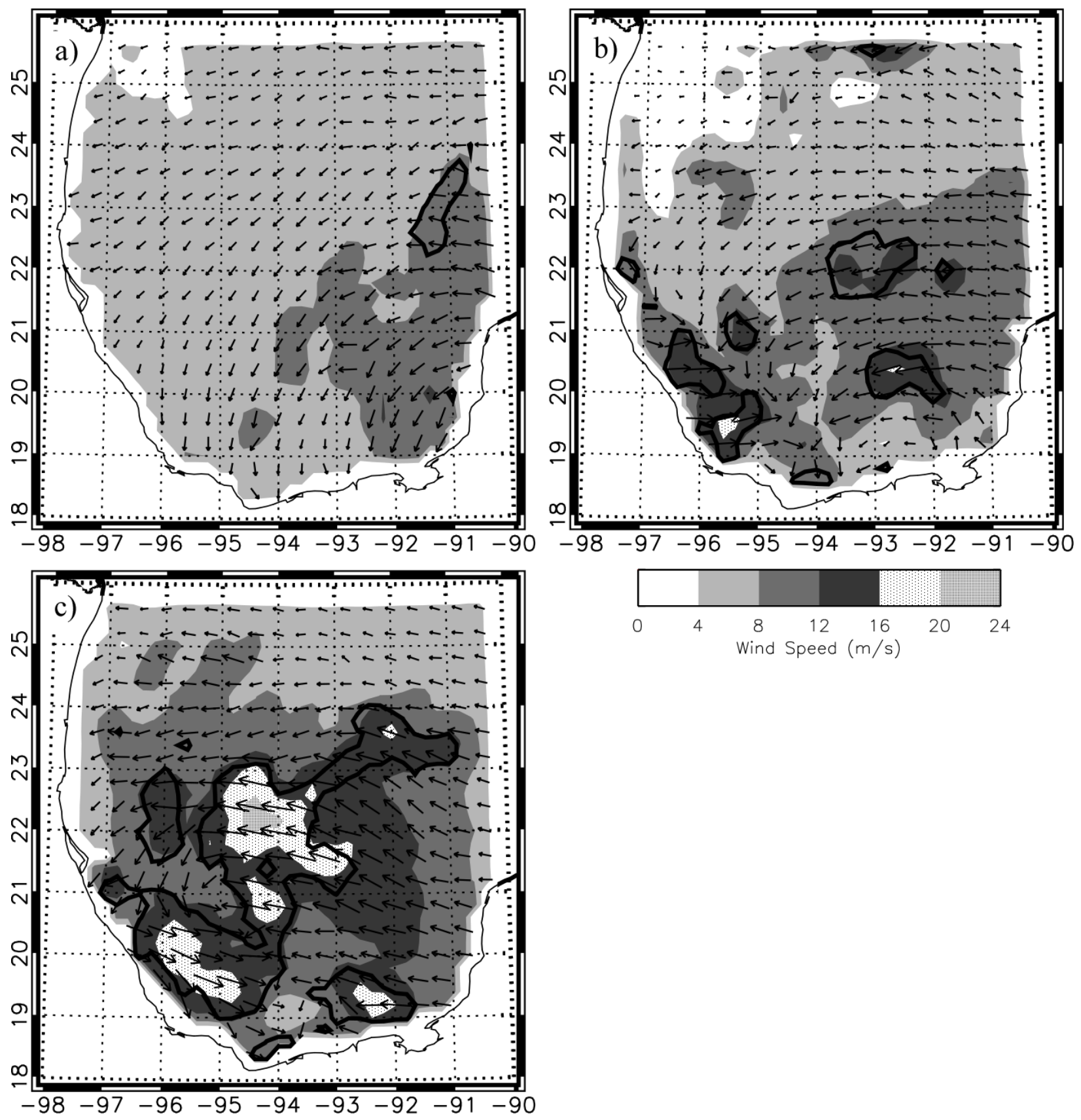

Figure 4. Quikscat wind speeds (shading) and vectors for (a) 01 UTC 23 July, (b) 12 UTC 23 July, and (c) 00 UTC 24 July. Areas enclosed within the bold solid line have a higher probability of rainfall contamination. 

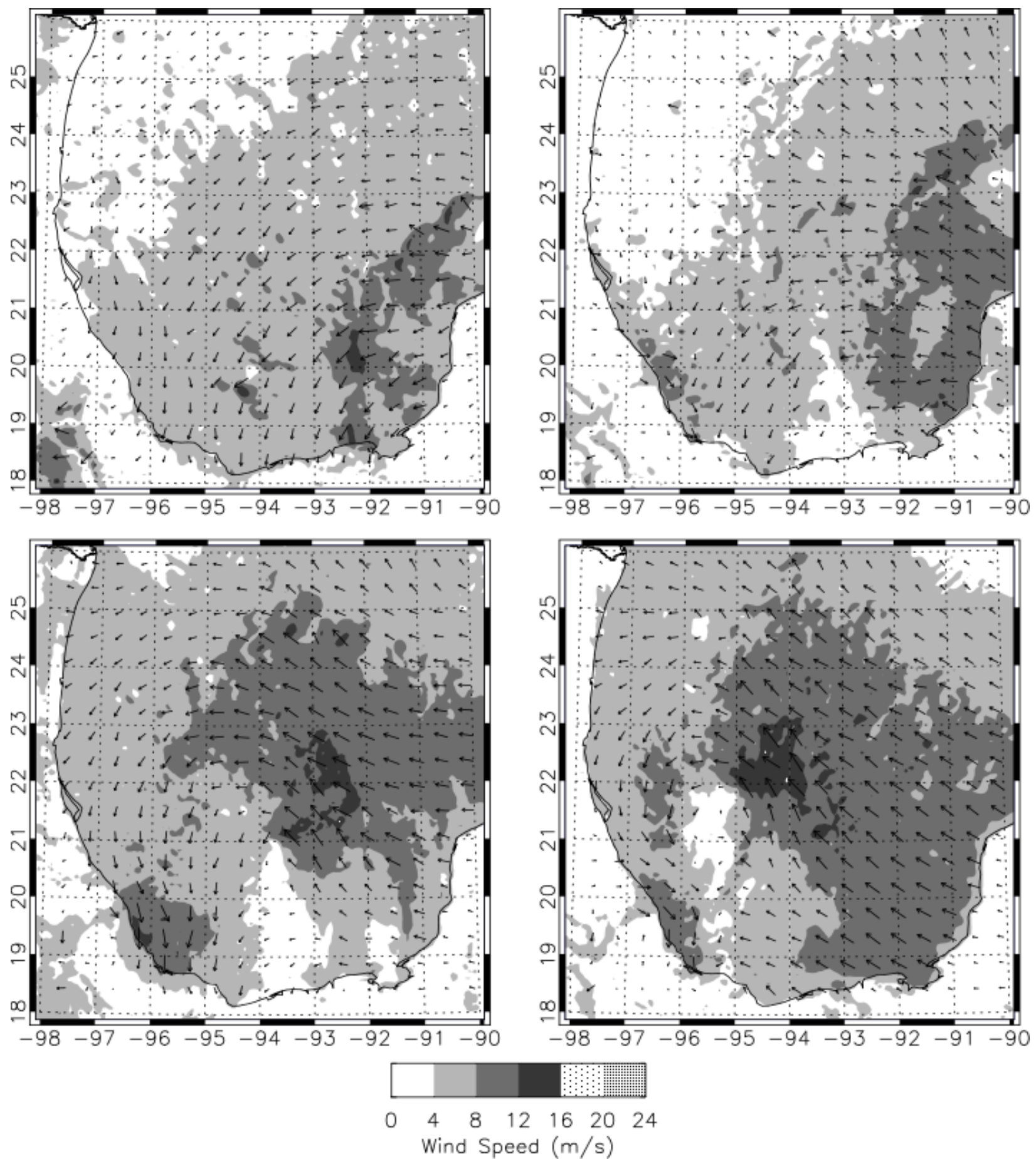

Figure 5. Simulated surface winds at (a) 00 UTC 23 July, (b) 12 UTC 23 July, (c) 00 UTC 24 July, and (d) 06 UTC 24 July. 

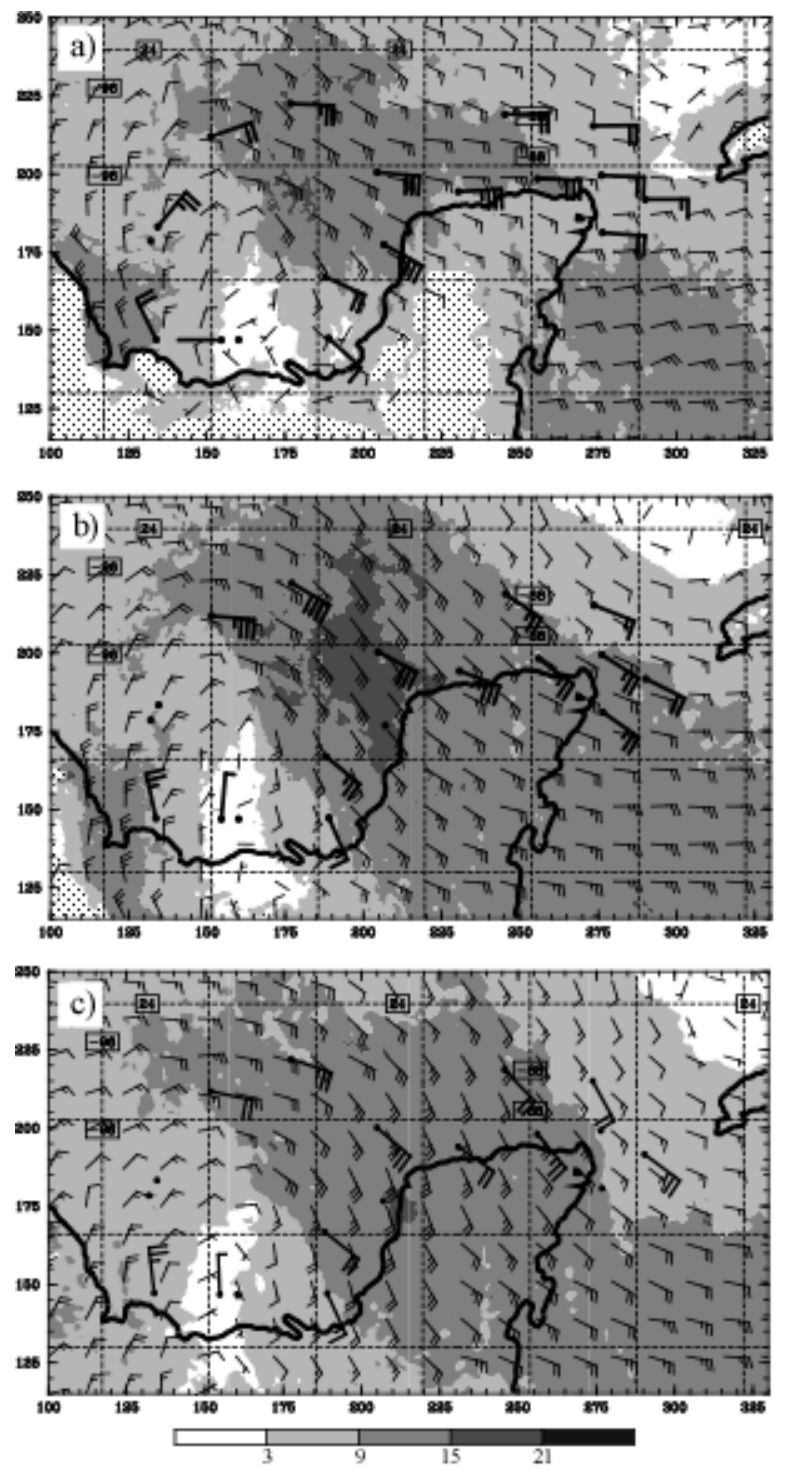

Figure 6. Simulated wind speeds and wind barbs (thin barbs) at (a) $1000 \mathrm{hPa}$, (b) $850 \mathrm{hPa}$, and (c) $700 \mathrm{hPa}$ at $21 \mathrm{UTC} 23$ July. Bold wind barbs indicate dropsonde winds at the same level. 

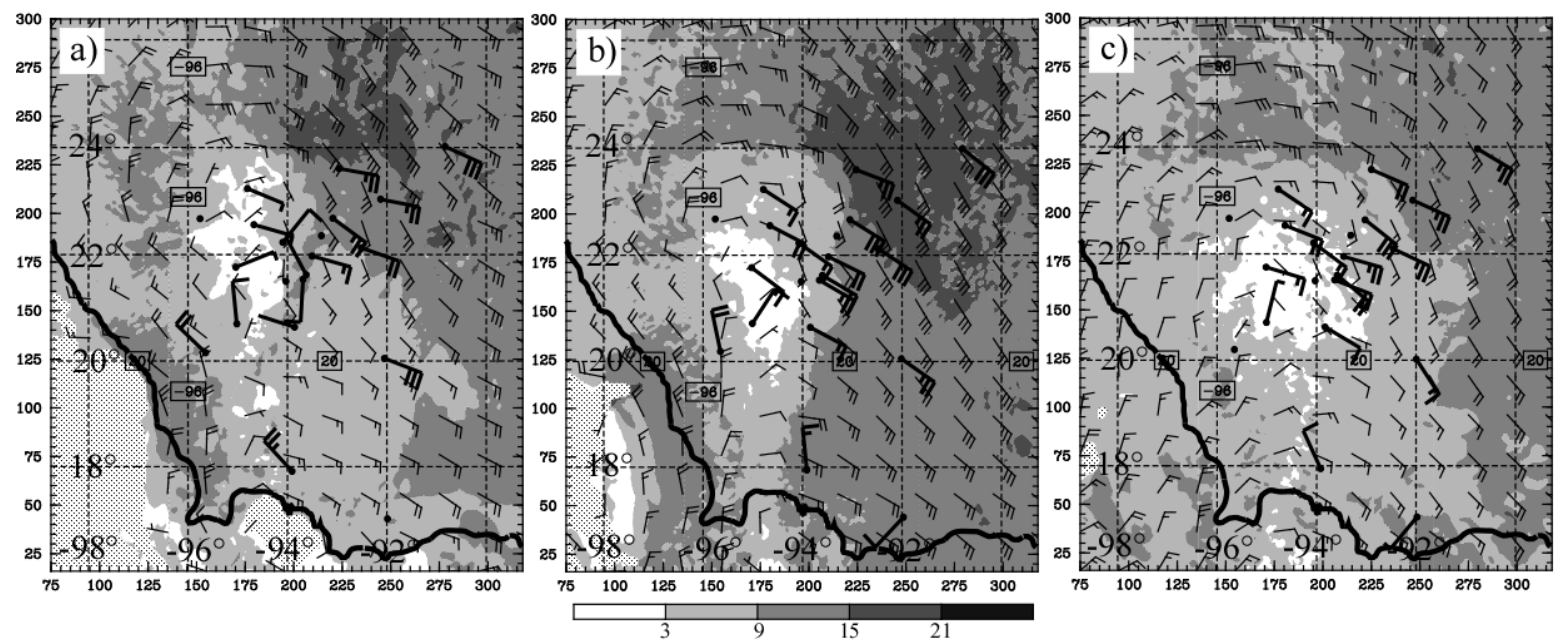

Figure 7. Same as in Fig. 6, but for 06 UTC 24 July. 


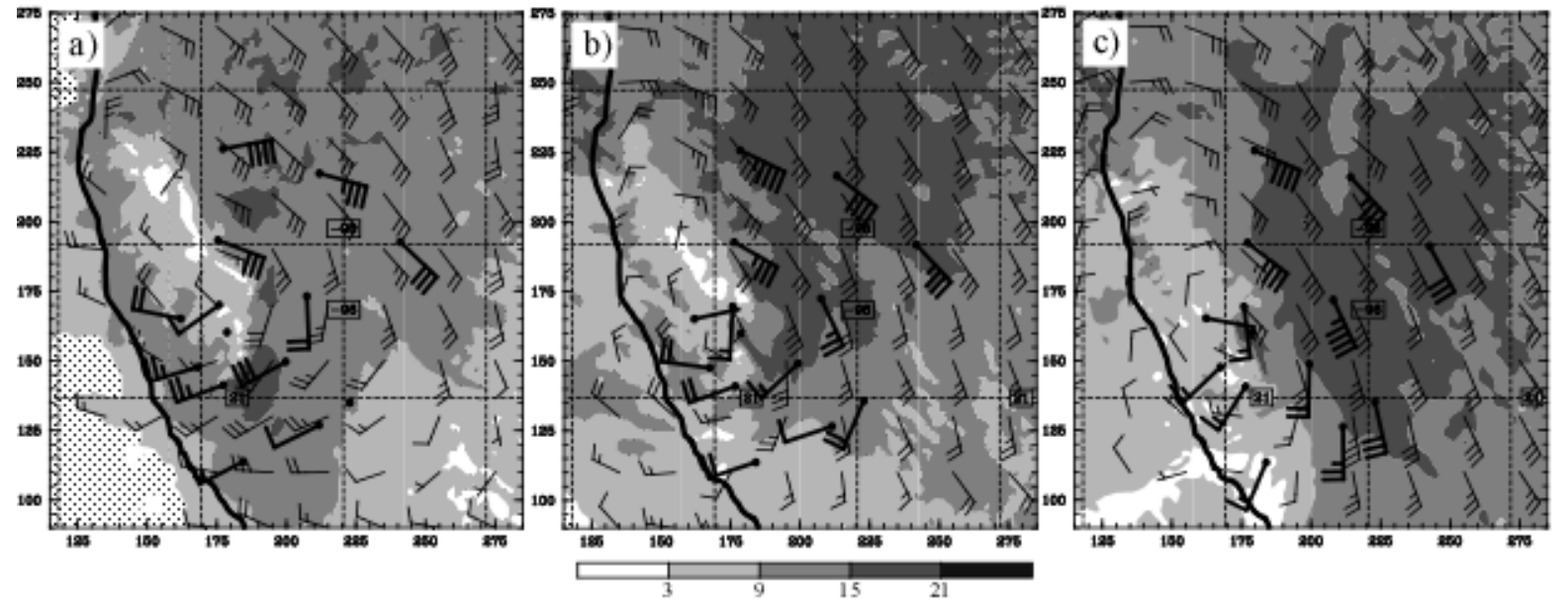

Figure 8. Same as in Fig. 6, but for 17 UTC 24 July. 


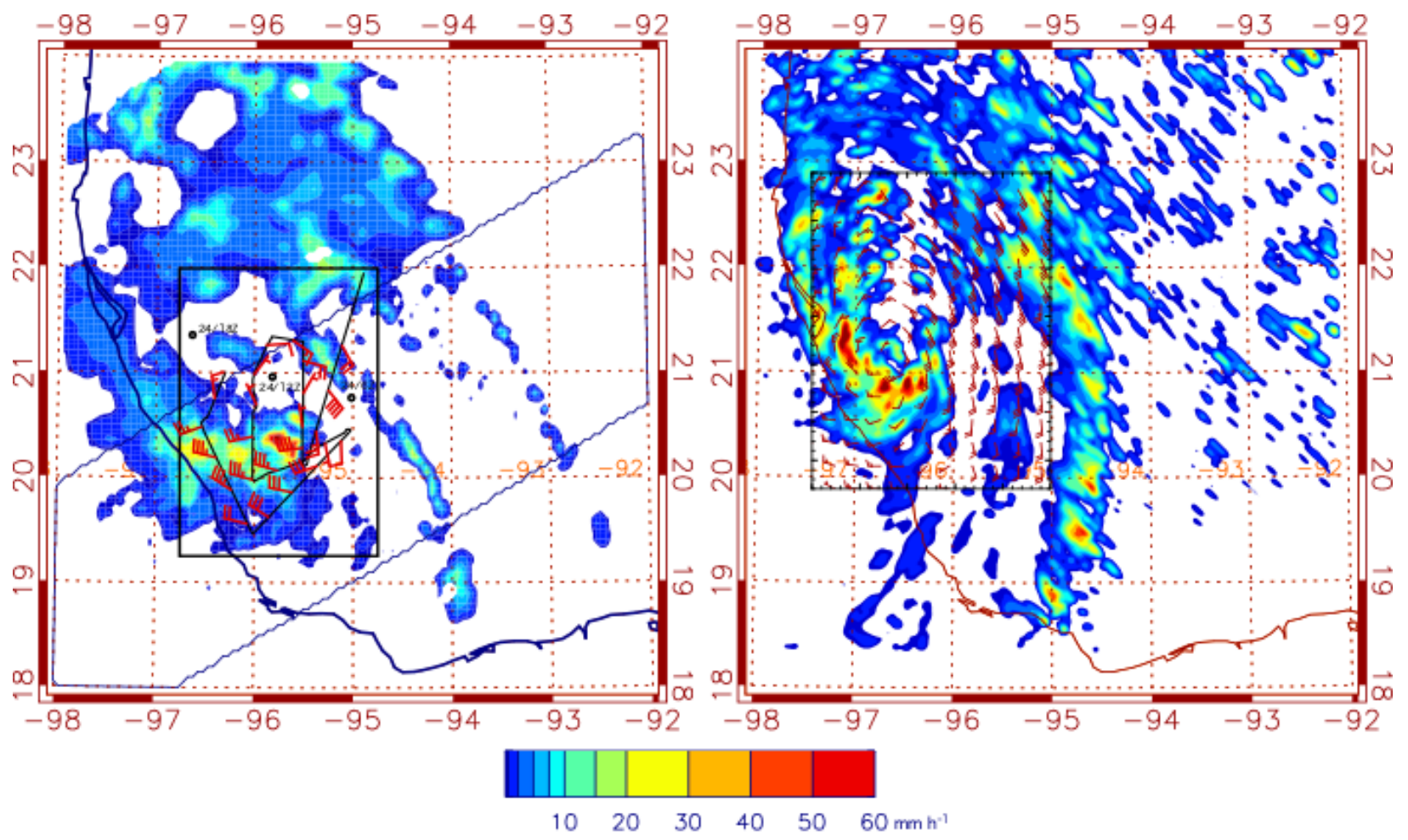

Figure 9. (a) TRMM derived rainfall rates at 1430 UTC 24 July. Thin black line indicates the track of an Air Force Recon flight and red wind barbs show in-situ boundary layer winds. (b) Simulated rainfall rates and 500-m level winds at 1430 UTC 24 July. 


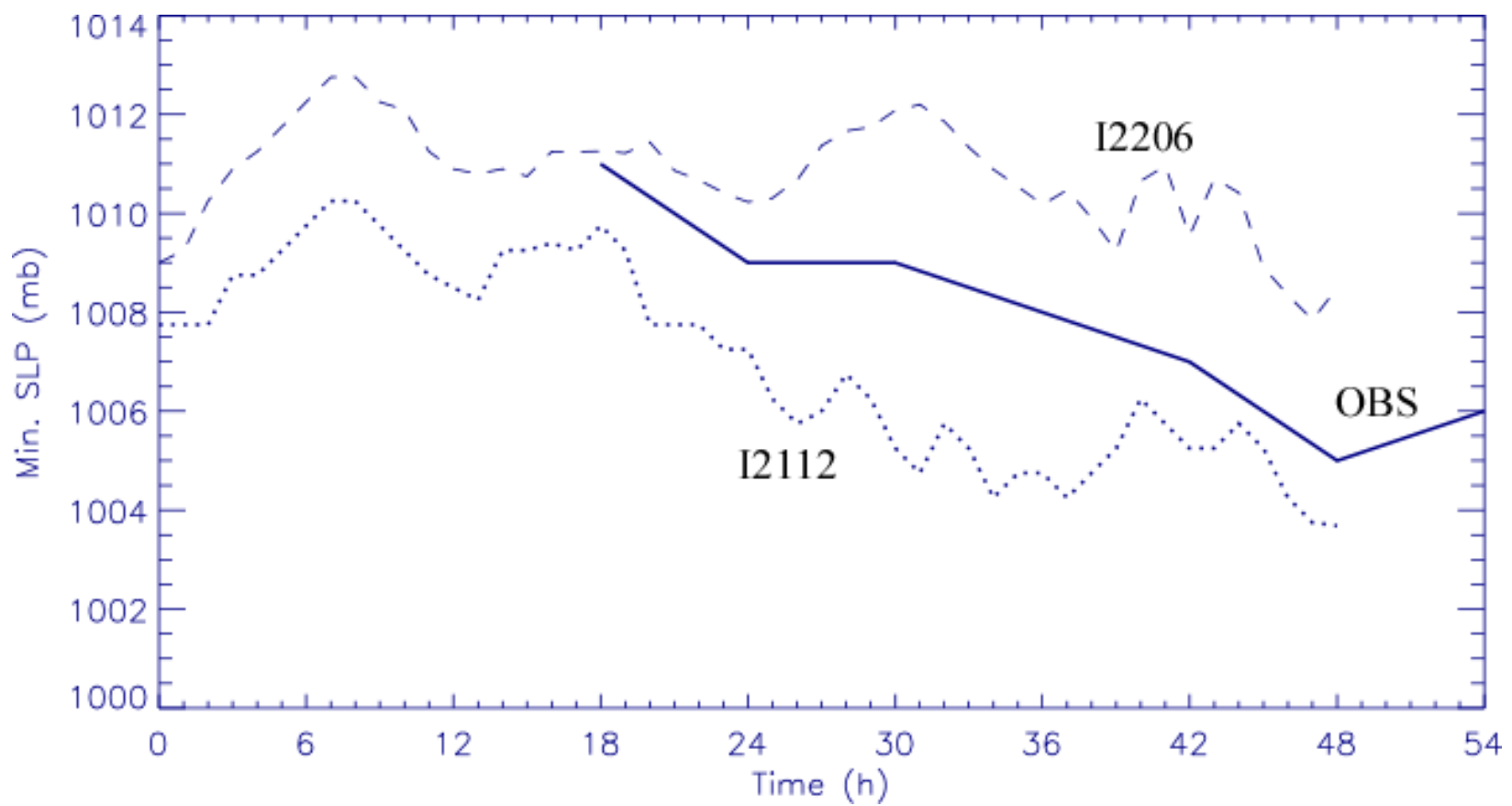

Figure 10. Time series of minimum sea level pressure from the observations (solid line), from the I2206 simulation (dashed line) and the I2112 simulation (dotted line). The time series of observed pressure begins at 00 UTC 23 July. 

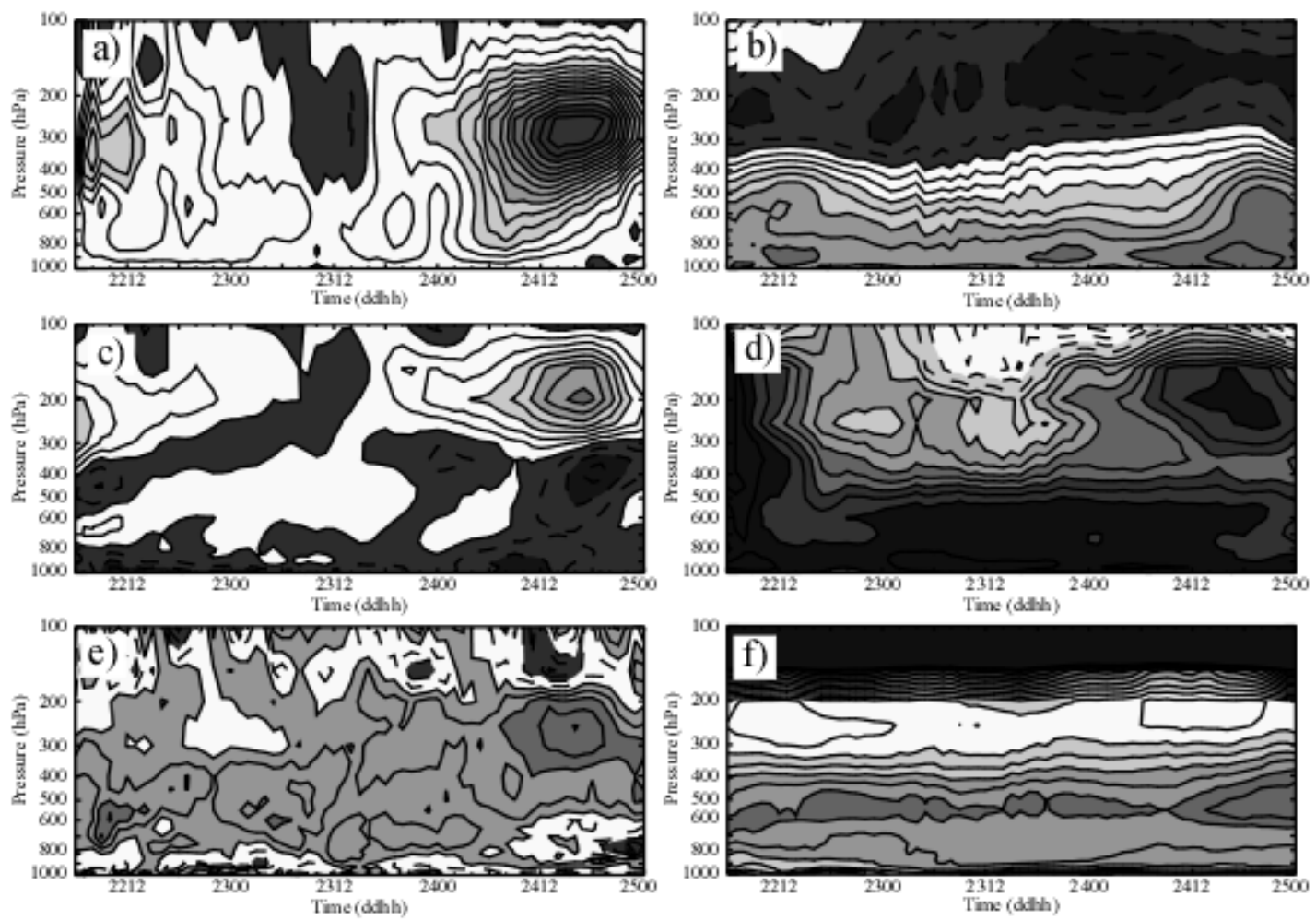

Figure 11. Time series of vertical profiles of area-averaged (a) vertical velocity $\left(1 \mathrm{~cm} \mathrm{~s}^{-1}\right.$ intervals), (b) tangential velocity ( $1 \mathrm{~m} \mathrm{~s}^{-1}$ intervals), (c) radial velocity ( $1 \mathrm{~m} \mathrm{~s}^{-1}$ intervals), (d) relative humidity (5\% intervals), (e) potential temperature perturbations ( $0.2 \mathrm{~K}$ intervals), and (f) potential vorticity (0.1 PVU intervals) for the I2206 simulation. 

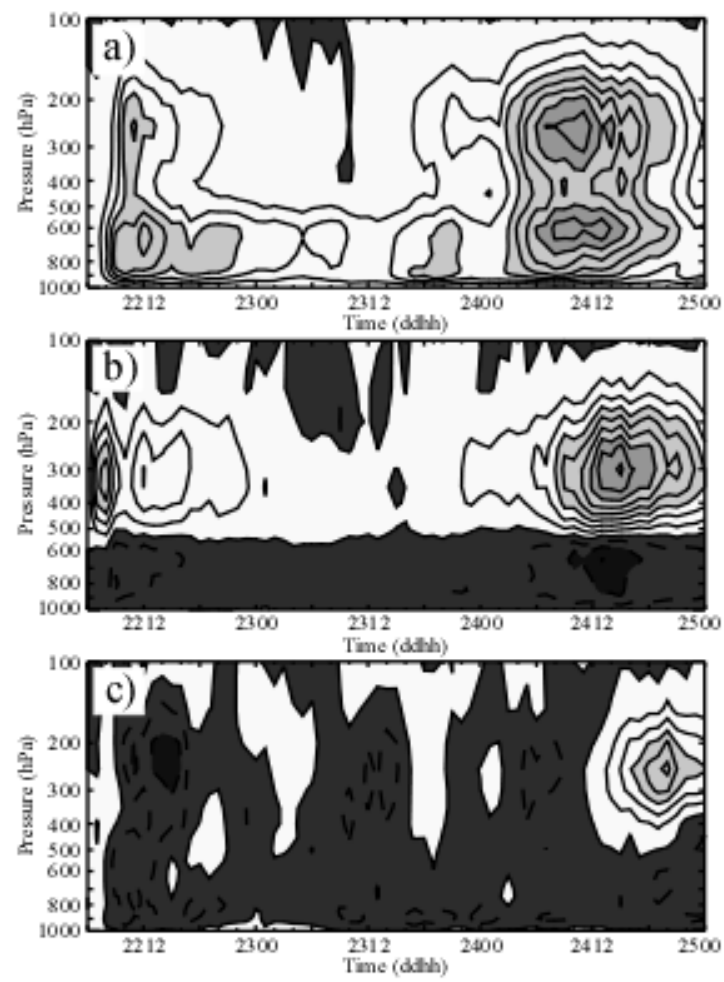

Figure 12. Time series of vertical profiles of the area-weighted average vertical velocity $\left(1 \mathrm{~cm} \mathrm{~s}^{-1}\right.$ intervals) in (a) convective, (b) stratiform, and (c) non-raining regions for the 22206 simulation. 

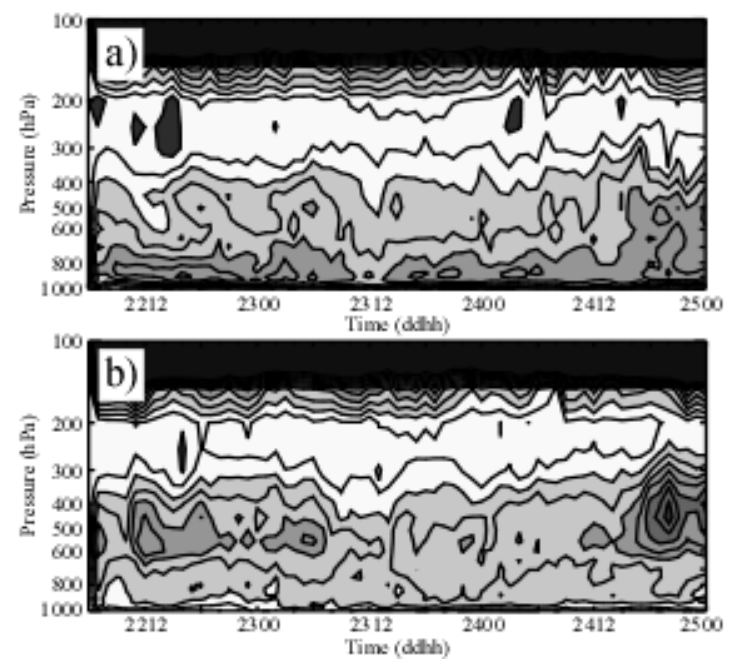

Figure 13. Time series of vertical profiles of the area- averaged potential vorticity $(0.2 \mathrm{PVU}$ intervals) in (a) convective and (b) stratiform regions for the I2206 simulation. 

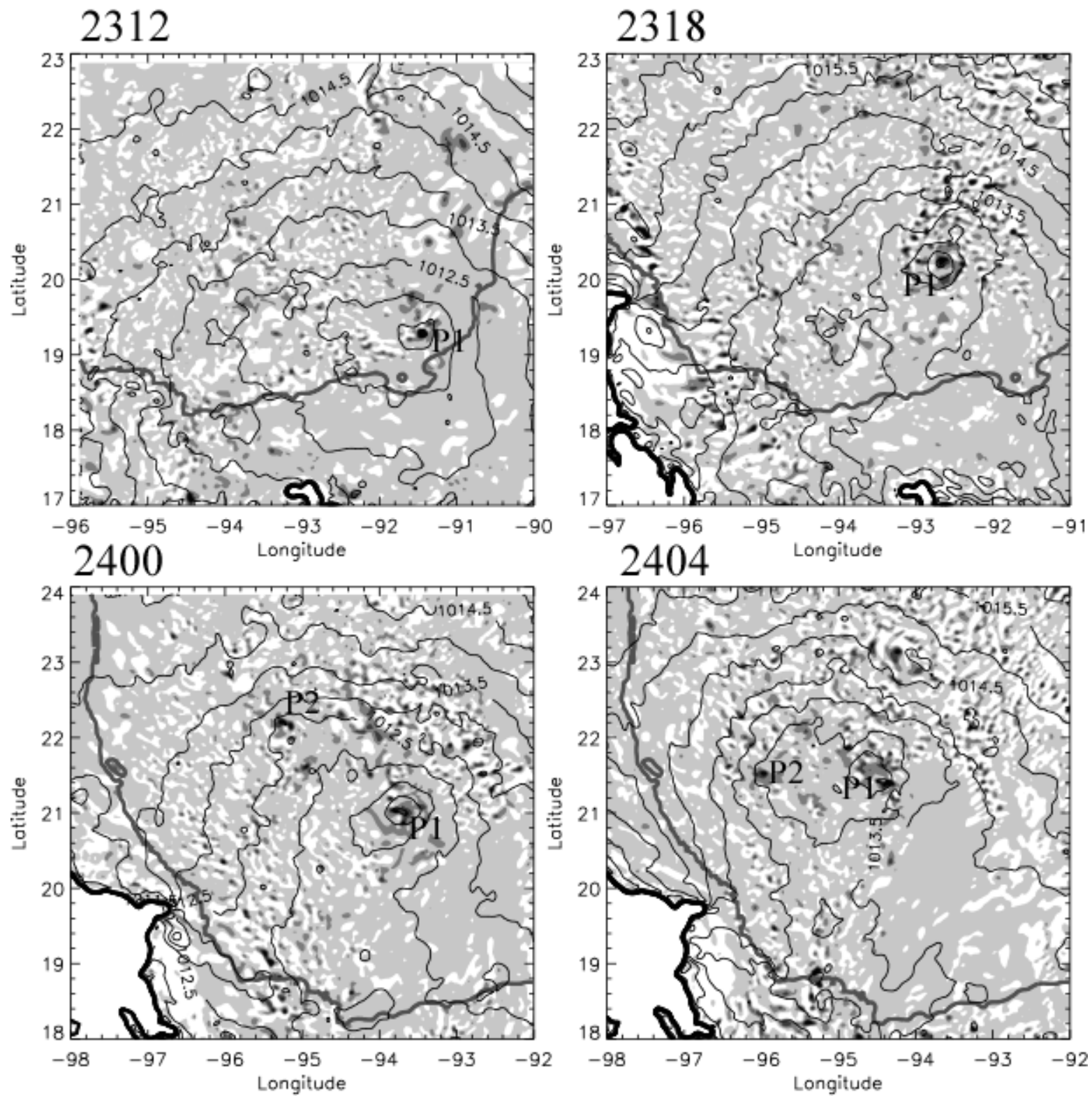

Figure 14. Sea-level pressure ( $0.5 \mathrm{hPa}$ intervals) and $850-\mathrm{hPa} \mathrm{PV}$ (shading) at (a) $12 \mathrm{UTC} 23$ July, (b) 18 UTC 23 July, (c) 00 UTC 24 July, (d) 04 UTC 24 July, (e) 08 UTC 24 July, (f) 12 UTC 24 July, (g) 18 UTC 24 July, and (h) 00 UTC 25 July. Negative PV regions are white and high PV regions are dark. The white areas bordered by the bold solid line indicates topography. 

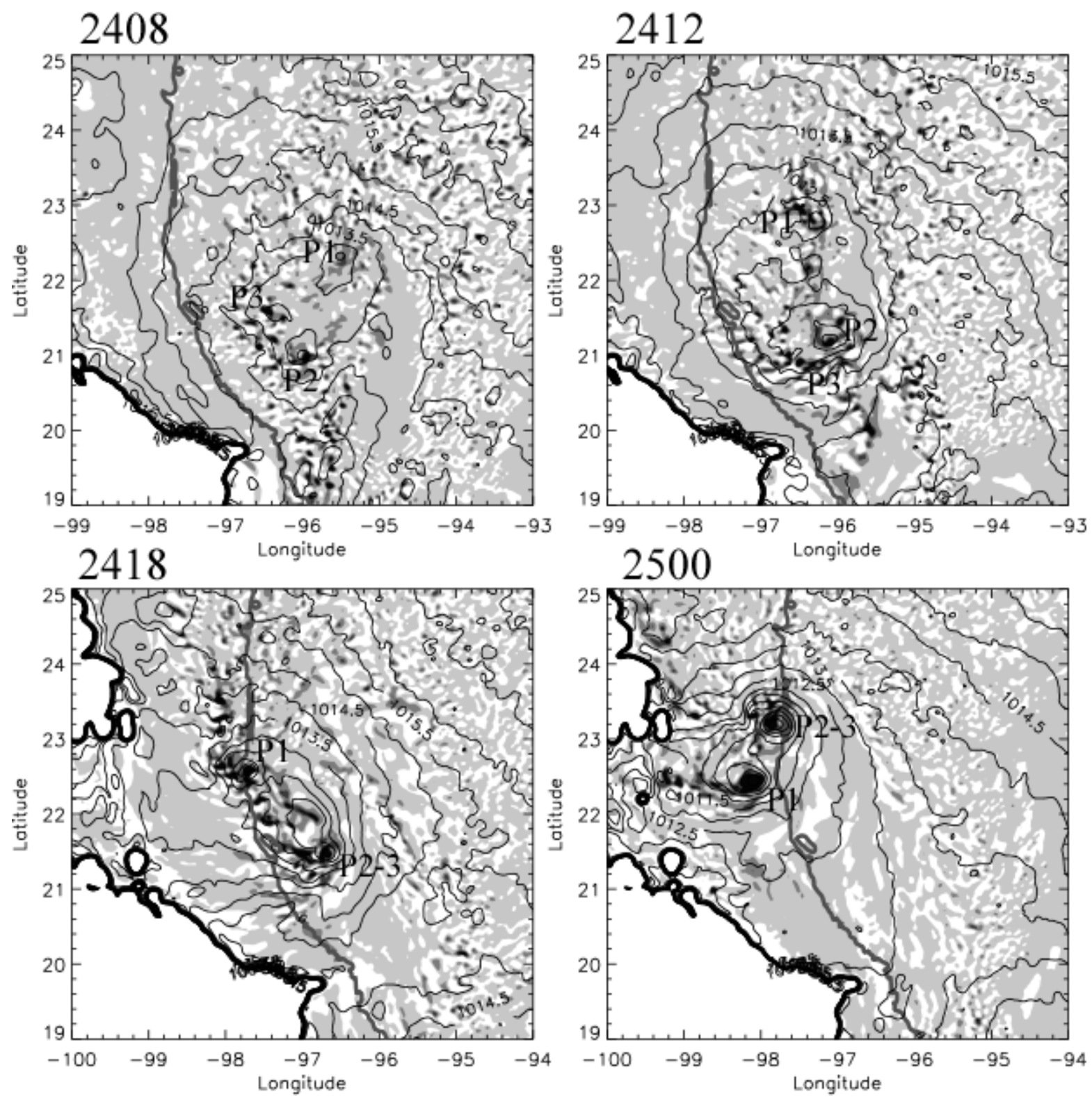

Figure 14 (continued). 

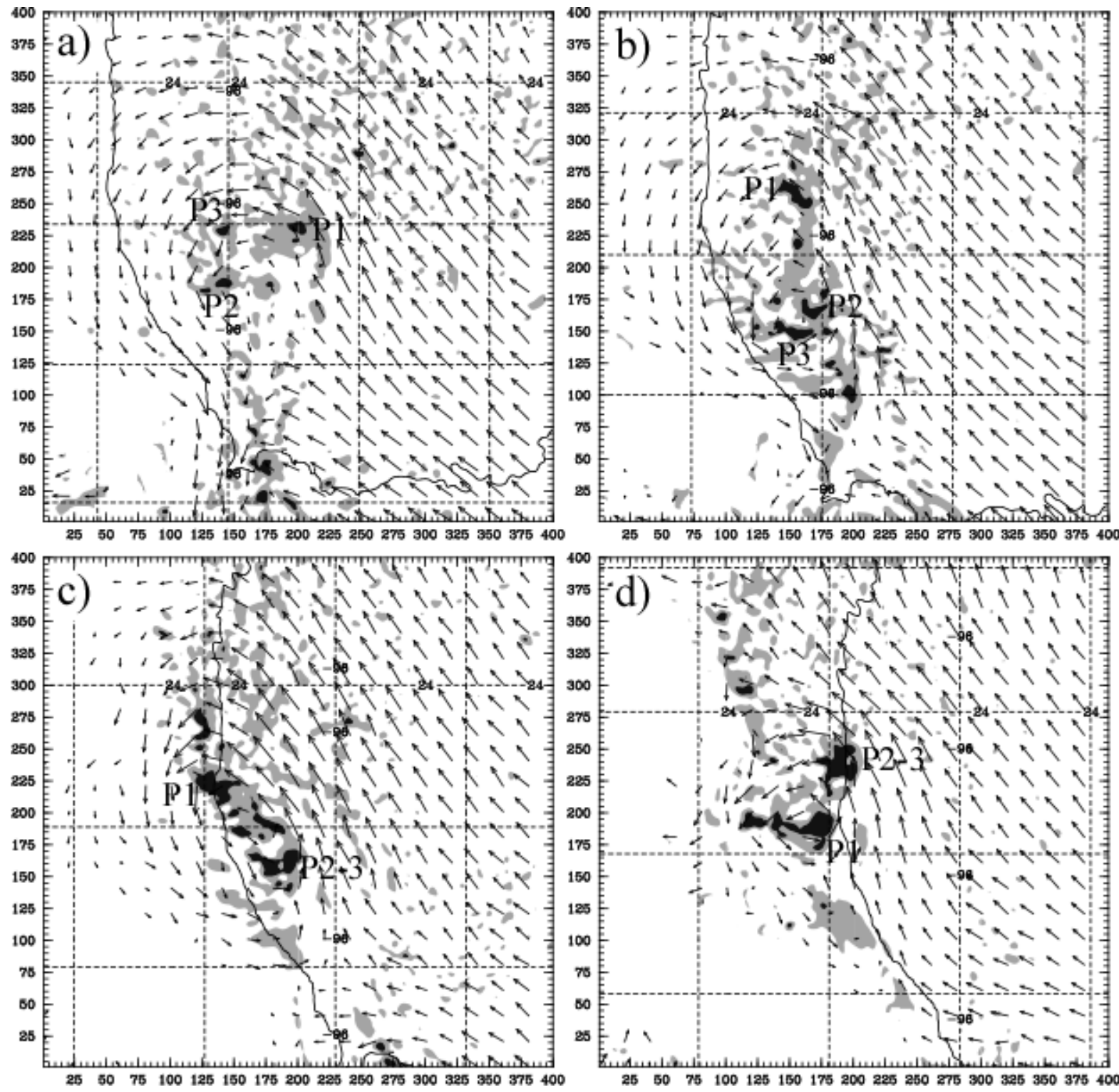

Figure 15. PV and vector winds at $850 \mathrm{hPa}$ at (a) $06 \mathrm{UTC}$, (b) 12 UTC, (c) 18 UTC 24 July and (d) 00 UTC 25 July. PV contours are at 1 and 3 PVU. 

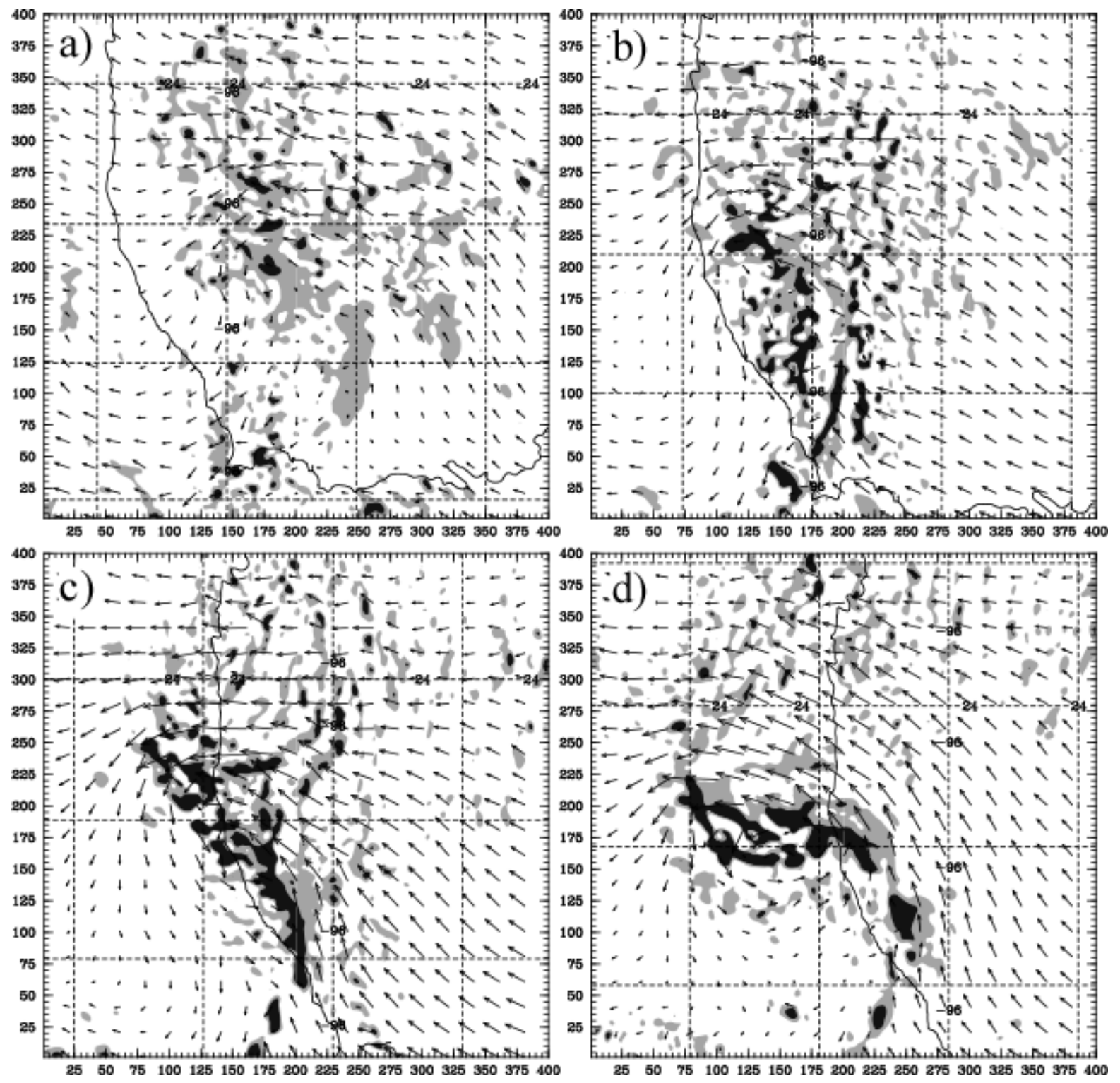

Figure 16. PV and vector winds at $500 \mathrm{hPa}$ at (a) $06 \mathrm{UTC}$, (b) 12 UTC, (c) 18 UTC 24 July and (d) 00 UTC 25 July. PV contours are at 1 and 3 PVU. 
a) 00 UTC 22 July

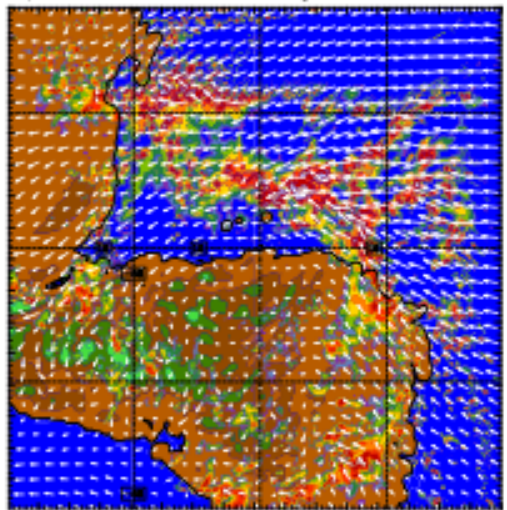

d) 12 UTC 23 July

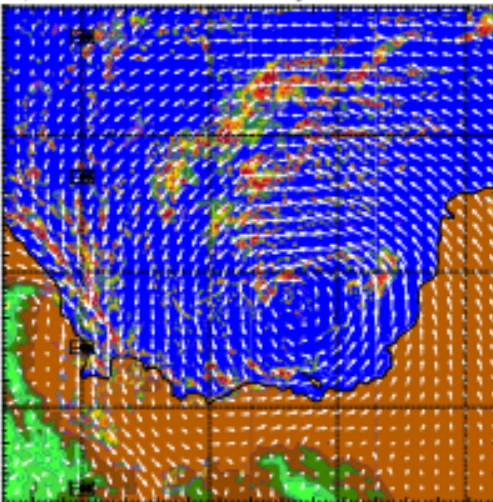

b) 06 UTC 22 July

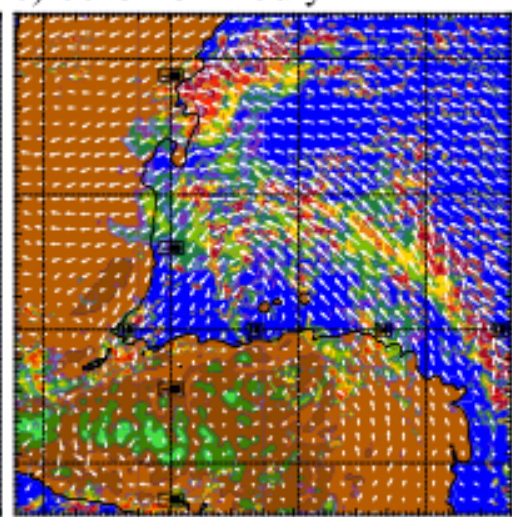

e) 06 UTC 24 July

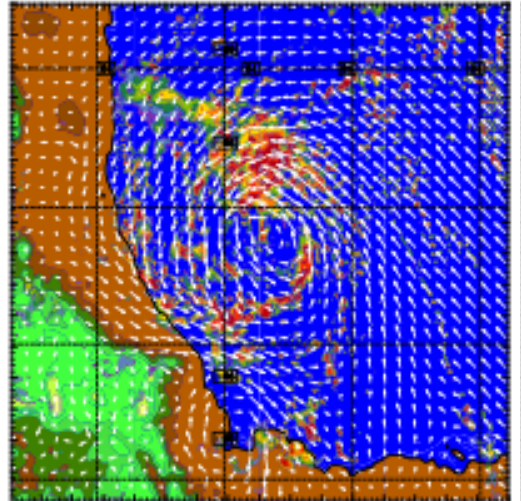

c) 12 UTC 22 July

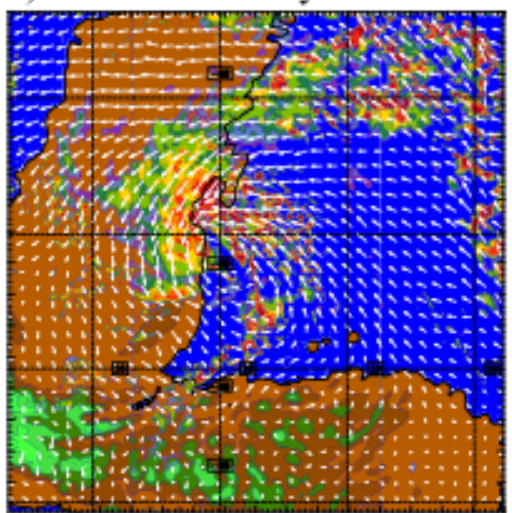

f) 18 UTC 24 July
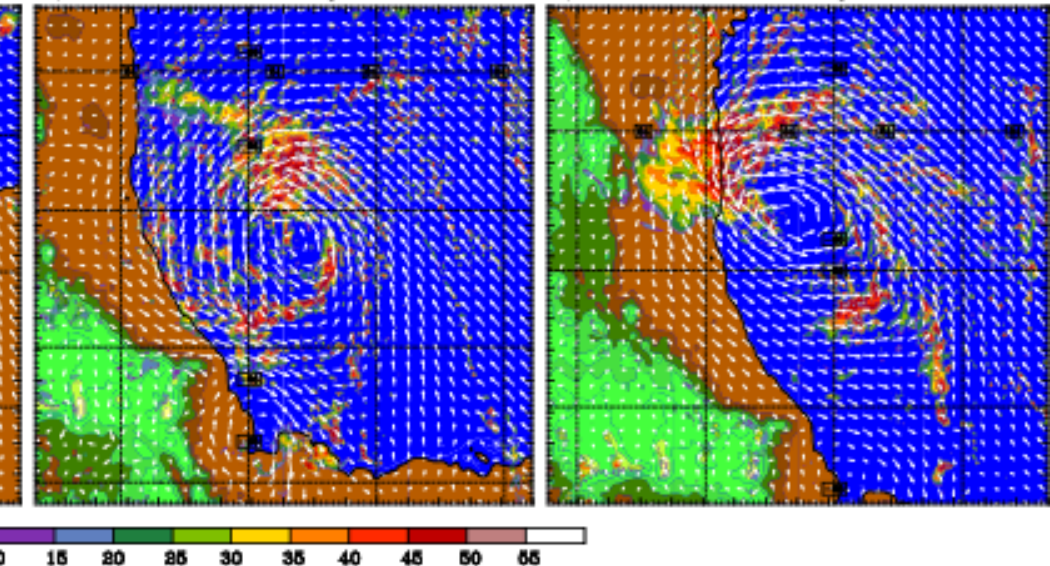

Figure 17. Simulated radar reflectivity and winds at $500 \mathrm{~m}$ altitude for the $\mathrm{I} 2112$ simulation. 

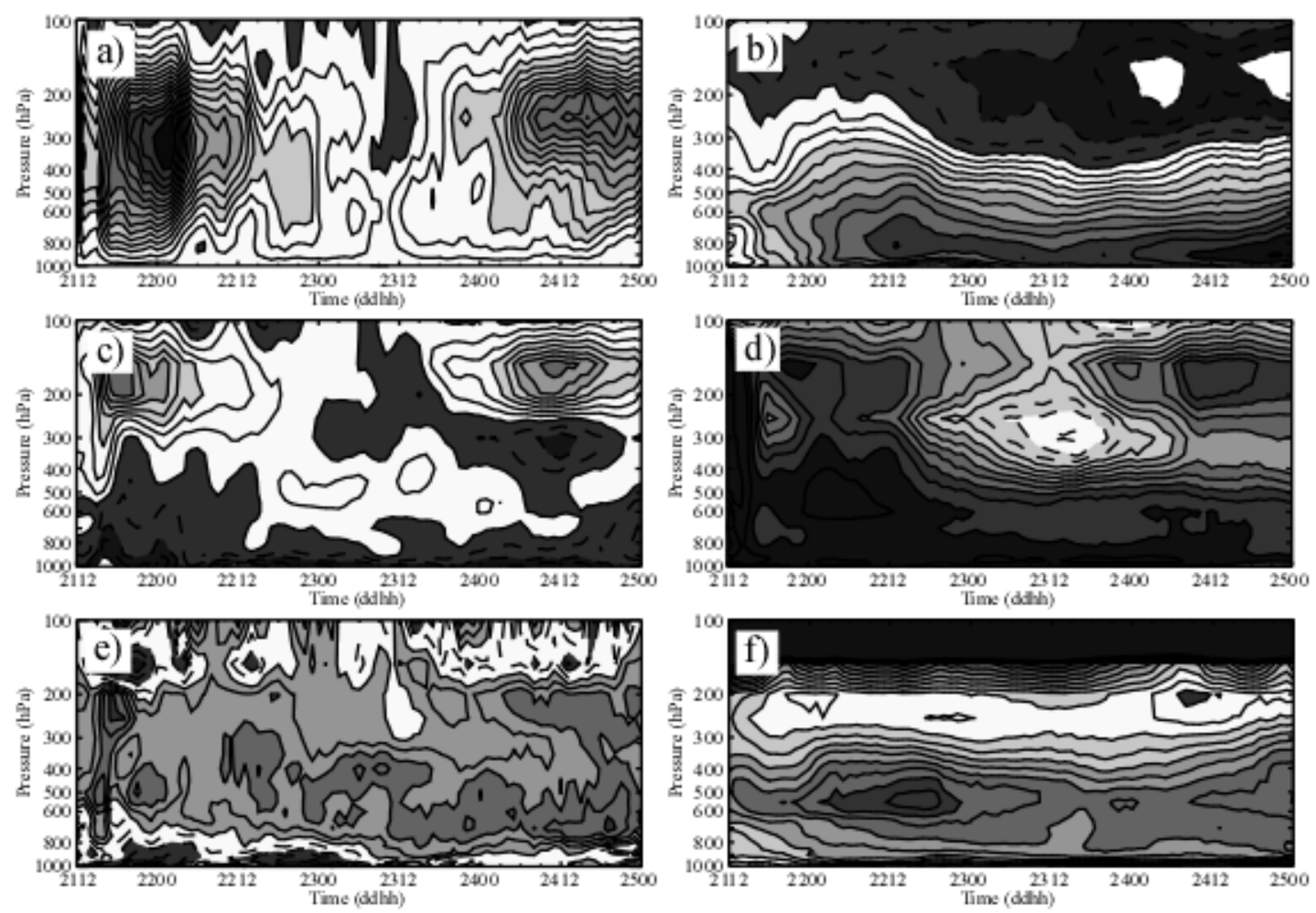

Figure 18. Time series of vertical profiles of area-averaged (a) vertical velocity $\left(1 \mathrm{~cm} \mathrm{~s}^{-1}\right.$ intervals), (b) tangential velocity ( $1 \mathrm{~m} \mathrm{~s}^{-1}$ intervals), (c) radial velocity ( $1 \mathrm{~m} \mathrm{~s}^{-1}$ intervals), (d) relative humidity ( $5 \%$ intervals), (e) potential temperature perturbations $(0.2 \mathrm{~K}$ intervals), and (f) potential vorticity (0.1 PVU intervals) for the I2112 simulation. 

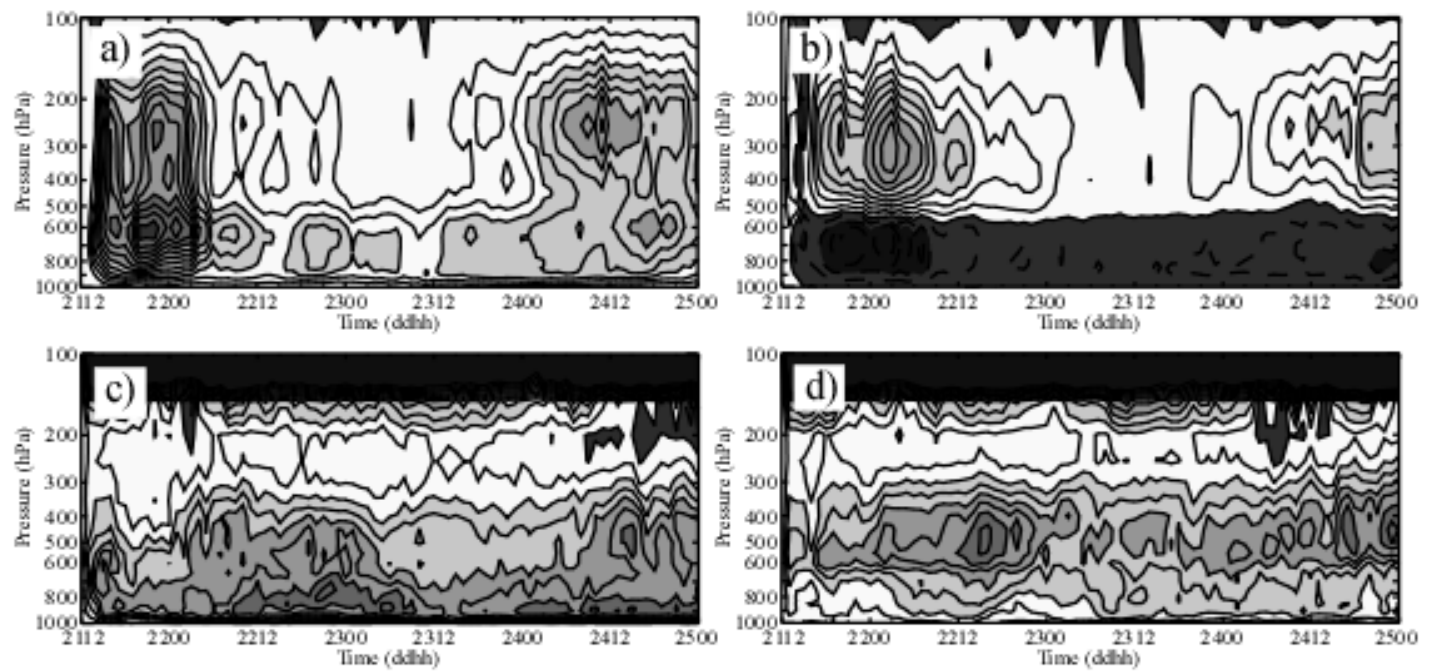

Figure 19. Time series of vertical profiles of the area-weighted average vertical velocity $\left(1 \mathrm{~cm} \mathrm{~s}^{-1}\right.$ intervals) in (a) convective and (b) stratiform regions for the I2112 simulation. In (c, d), vertical profiles of the area-averaged potential vorticity (0.2 PVU intervals) in (c) convective and (d) stratiform regions. 

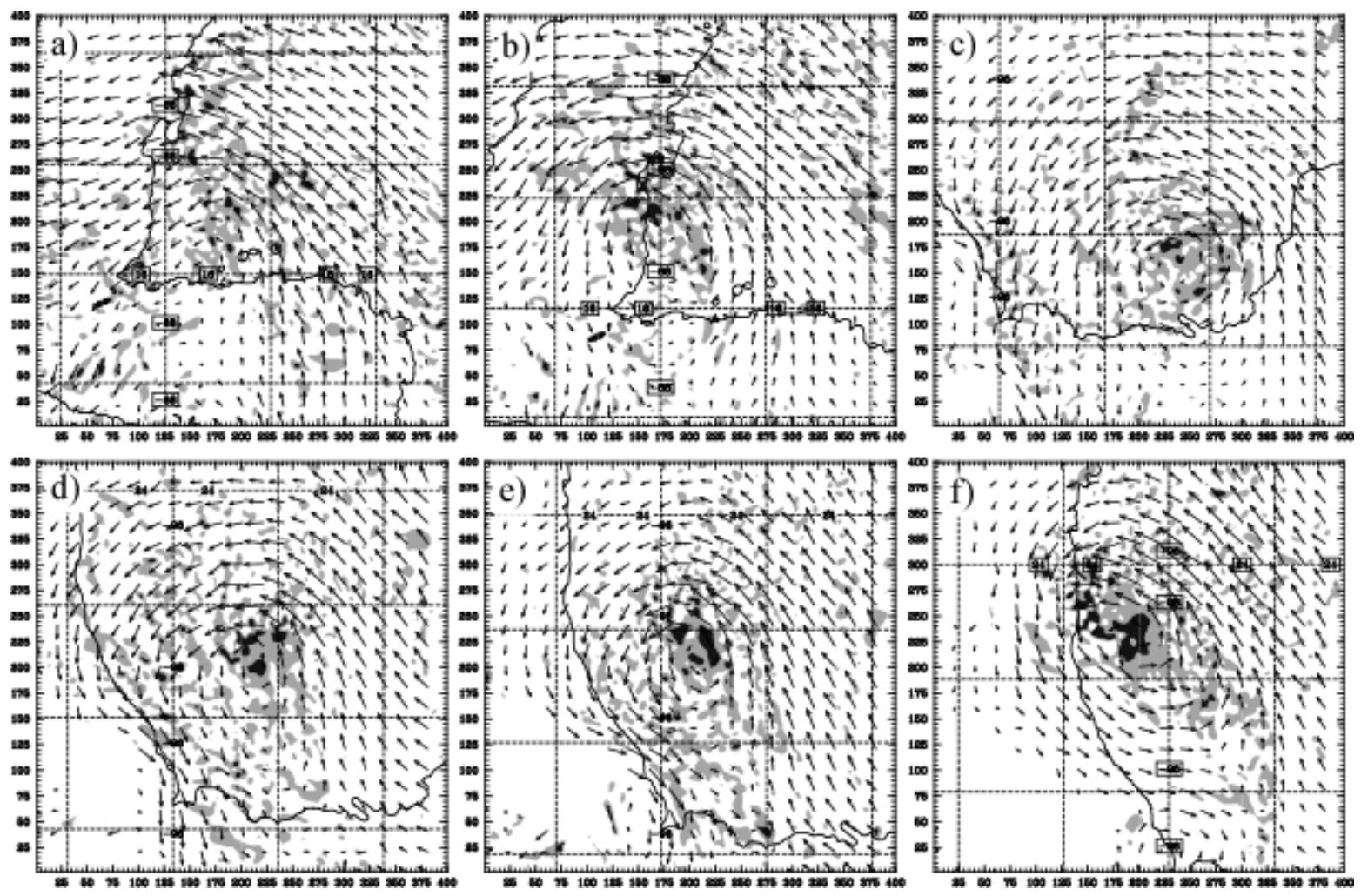

Figure 20. PV and vector winds at $850 \mathrm{hPa}$ at (a) 06 UTC 22 July, (b) 12 UTC 22 July, (c) 12 UTC 23 July, (d) 00 UTC 24 July, (e) 06 UTC 24 July, and (f) 18 UTC 24 July for the I2112 simulation. PV contours are at 1 and $3 \mathrm{PVU}$. 

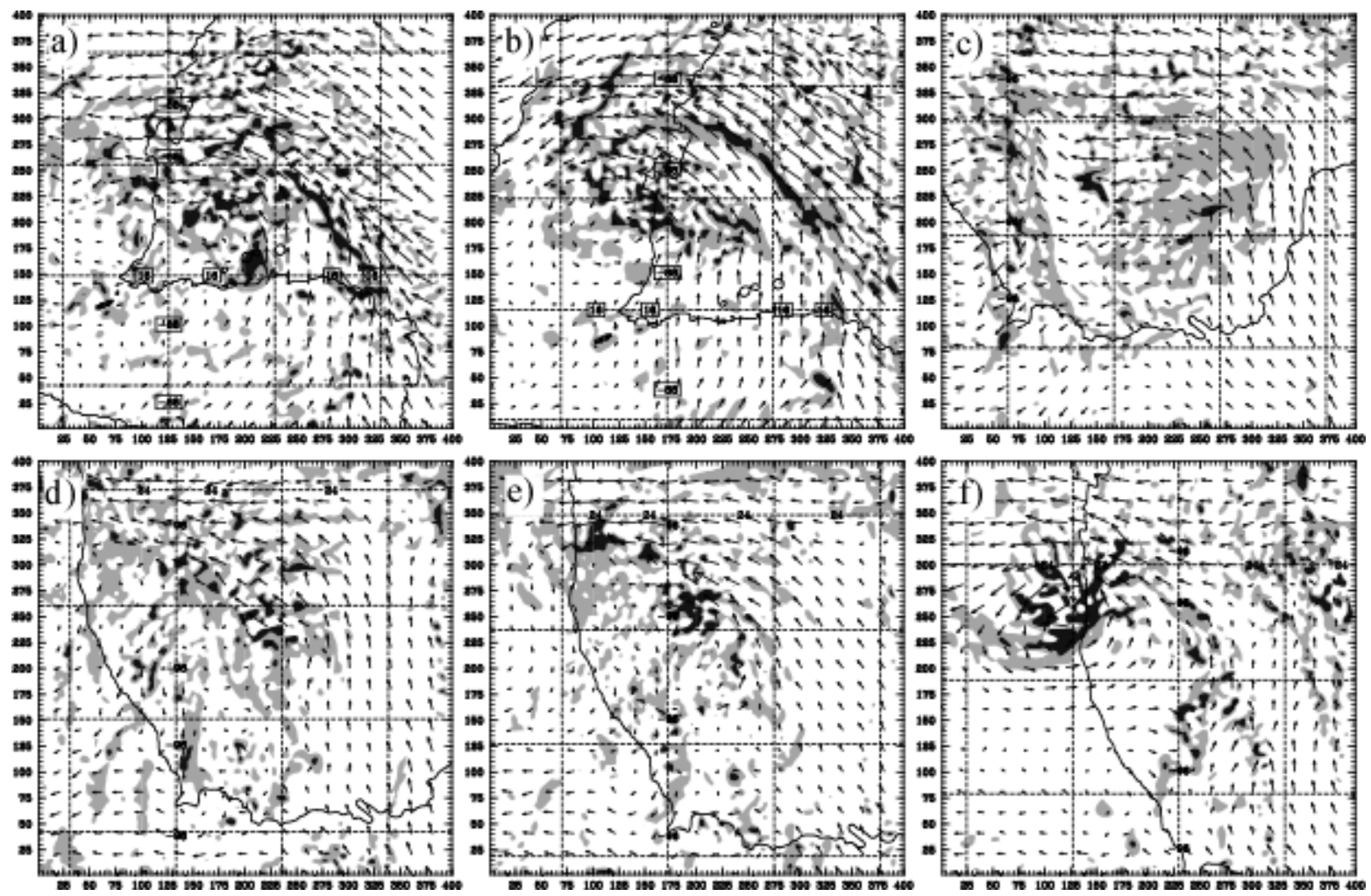

Figure 21. PV and vector winds at $500 \mathrm{hPa}$ at (a) 06 UTC 22 July, (b) 12 UTC 22 July, (c) 12 UTC 23 July, (d) 00 UTC 24 July, (e) 06 UTC 24 July, and (f) 18 UTC 24 July for the I2112 simulation. PV contours are at 1 and $3 \mathrm{PVU}$. 